\title{
Analytical clothing model for sensible heat transfer considering spatial heterogeneity
}

\section{Abstract}

5 Existing clothing models assume spatial homogeneity of the enclosed air layer between skin and fabric, which contradicts real-life scenarios. Furthermore, depending on the thickness of enclosed air layer and the temperature difference between skin and fabric, natural convection may occur but it is often neglected in the theoretical models. In this study, we have developed a theoretical model that considers the spatial heterogeneity of enclosed air layer and natural convection. It computes the sensible heat transfer (conduction, radiation and natural convection) in the heterogeneous enclosed and boundary air layers. The heat transfer in the clothing layer is calculated based on the thermal resistance of the fabric.

The model presented in this paper is systematically validated for natural convection and spatial heterogeneity using a thermal cylinder and a thermal manikin with increasing level of spatial complexity. The validation of the model was performed for a wide range of temperatures $\left(-10^{\circ} \mathrm{C}\right.$ to $\left.26^{\circ} \mathrm{C}\right)$, enclosed air layer thicknesses (homogeneous and heterogeneous), and ambient air speeds $(0.2 \mathrm{~m} / \mathrm{s}, 1 \mathrm{~m} / \mathrm{s})$ and demonstrated a good agreement between predicted and measured heat flux with an average error of $3.7 \%$ and $9.3 \%$ for homogeneous and heterogeneous enclosed air layers, respectively.

\section{Keywords}

Heat transfer, Heterogeneous air gap, Natural convection, Theoretical clothing model, Intersegmental convective heat exchange, Local clothing properties. 


\section{Introduction:}

Thermoregulation of human body aims at maintaining body core temperature in a narrow range and depends on metabolic heat production and the exchange of heat between skin and environment. When the human body is covered with clothing, it affects human physiological regulation mechanisms. Thus, the design and material aspects of functional clothing (e.g. protective or sport clothing) requires a detailed understanding of heat transfer processes. In the clothing research, heat transport is usually assessed by hot plates, thermal cylinders or thermal manikins in steady-state measurements. The experimental methods of assessing heat transfer require the availability of prototypes and testing facilities (e.g. climatic chambers) [1] , which can be costly and time-consuming. On the other hand, the theoretical modelling provides many advantages over experimental measurements, such as no prototype requirement, modelling of wide range of ambient conditions, detailed insight to the heat transfer process, and a timeefficient optimization of the product through parametric study.

The thermal conductivity of stagnant air $(0.026 \mathrm{~W} /(\mathrm{mK})$ at $300 \mathrm{~K})$ is very low compared to most of the fibres, which makes it a good thermal insulator. Therefore, the enclosed air layer (air layer between skin and clothing layers) has a more pronounced effect on total heat transfer than actual fabrics constituting the garment. Depending on the thickness of enclosed air layer and the temperature difference between clothing layers and skin, natural convection may reduce the insulation of the air layers due to buoyancy effect. The density difference in fluid due to temperature gradient results in onset of buoyancy force and hence fluid motion (natural convection). The natural convection inside a cavity is complex phenomenon and depends on its size and shape (aspect ratio is a ratio of height to width), orientation of geometry, and temperature difference between enclosing walls (e.g. skin and clothing temperatures). For horizontal and vertical cavity, the natural convection was observed for minimum enclosed air layer thickness of $13 \mathrm{~mm}$ and $8 \mathrm{~mm}$, respectively [2, 3]. Most of the theoretical clothing models have neglected natural convection in an enclosed air layer [4-7]. For example, the only mathematical model considering natural convection in boundary air layer but neglecting it in enclosed air layer was developed by Min et al. [8]. Since, the thickness of enclosed air layer in clothing was not addressed till recently, it was not possible to characterize the magnitude of natural convection heat transfer properly. Recent developments of 3D scanning methods made it feasible to determine the thickness and its spatial distribution of the enclosed air layer with great accuracy $[9,10]$. A detailed distribution of enclosed air gap enables the computation of local heat transfer for individual body parts.

Until now, all the theoretical models assume either full contact area or homogeneous air layer between skin and different layers of clothing [4-6, 8, 11-14]. This assumption contradicts a realistic scenario of skin and clothing layer system and affects the accuracy of the simulated heat flux by the theoretical model. Therefore, consideration of only average air gap thickness is not sufficient (as thermal resistance of air layer is non-linearly related to the air gap thickness) and orientation of air gap and contact area affects the heat flux. As shown in Figure 1 (b), heat flux can vary up to $26-28 \%$ for the same average air gap thickness [15]. Another 
model attempting investigation of the effect of heterogeneous air gap on thermal protective clothing was reported by Udayraj et. al, [16]. However, only small folds in a large distance from the horizontal plate (as opposed to realistic large and small folds and accompanying contact with skin) were investigated and results were not validated against the experimental data. The accuracy of clothing model largely depends on the input data and especially accuracy of the air gap thickness input as the majority of thermal insulation is due to the low thermal conductivity of enclosed air. Ismail et. al, [14] also developed a model that predicts the segmental heat loss in static and dynamic condition. However, their assumption of air gap thickness on the major body parts was unrealistic for single and multi-layer garments (assumed $5 \mathrm{~cm}$ for trunk and $4 \mathrm{~cm}$ for leg, which was 2-3 times beyond the 3D scanned data reported for loosest garments [17] [18]), which questions the overall model quality. The model developed by Ghali et. al, [19] considered periodic contact between skin and cotton fabric with still homogeneously varying air gap on a horizontal flat plate with poor validation record (reported relative error of $\approx 35 \%$ in heat loss validated on just one case). Since this is not a realistic representation of enclosed air layer around human body, the applicability and accuracy of the model is uncertain for the heterogeneous enclosed air layers.

The distribution of air gap in an enclosed air layer depends on clothing fit level (ease allowance), body posture, and body region [17, 18, 20-23]. The mean thickness of enclosed air layer at different body regions can vary between 0 to $55 \mathrm{~mm}$, while contact area between skin and fabric was observed in the range of $0-60 \%$ of the covered body area [24]. As shown in Figure 1(a), the thickness of enclosed air layer and contact area varies depending on the body part, and therefore the distribution of air gap is spatially heterogeneous. Furthermore, in a study by Psikuta et al. [24], a more general trend in distribution of air gap thickness in casual clothing was revealed that for all body parts except chest and back, enclosed air gap thickness increases with increase in ease allowance. On the other hand according to the Fourier's law of heat conduction, the thickness of enclosed air layer could have pronounced effect on conductive heat loss. Similarly, according to Stefan-Boltzmann's law orientation of adjacent surfaces and heterogeneous clothing temperature can influence the radiative heat loss. Moreover, natural convection depends on the length and thickness of enclosed air layer [25, 26]. Thus, heterogeneity in the thickness of enclosed air layers and the contact area between different layers of fabric and skin has a significant effect on heat transfer [15]. 
(a)

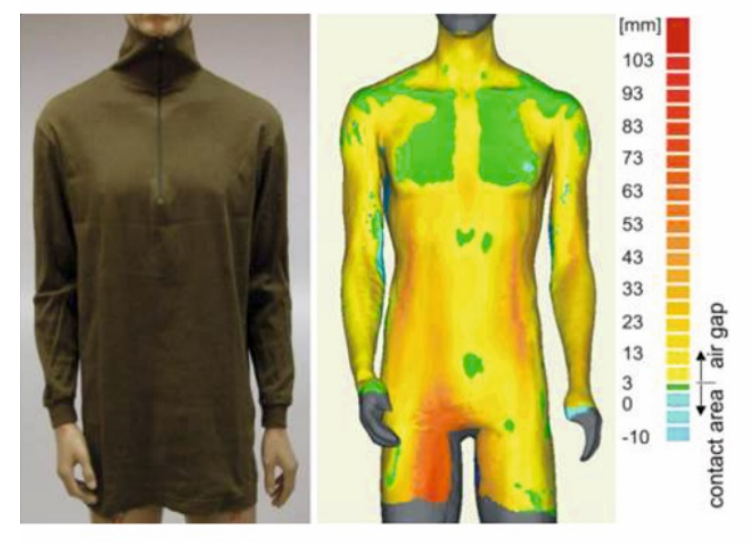

(b)

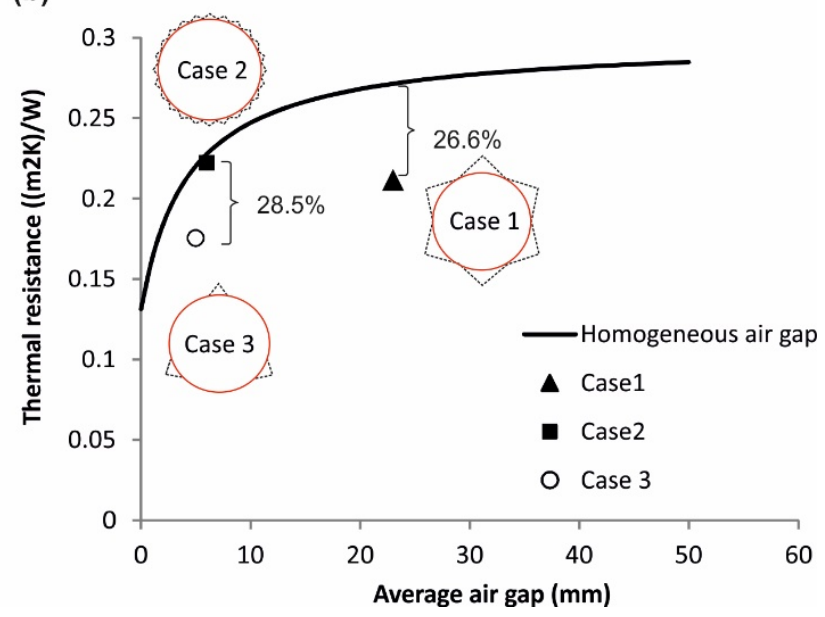

Figure 1 Distribution of air gap thickness and spatial heterogeneity in the enclosed air layer for a long shirt(a), Thermal resistance for various homogeneous and heterogeneous air gap thickness systems (b) [15]

The aim of this study was to develop a theoretical clothing model that considers not only conduction through the fabric and conduction and radiation in the air layers but also the spatial heterogeneity of enclosed air layer and natural convection. As an effort to provide more reliable and accurate theoretical model, the results of the theoretical model are systematically validated against experimental data with increasing level of complexity in definition of the enclosed air layer measured on the thermal cylinder and thermal manikin. Finally, a parametric study is also performed to understand the effect of various parameters such as emissivity of fabric, ambient air velocity and temperature, and contact area, on sensible heat transfer and different heat transfer mechanisms. 


\section{Methods and procedure}

\subsection{Assumptions made for the heat transfer model in a skin-clothing-environment system}

To understand the heat exchange between human body and environment through the clothing, the entire system can be divided into three different segments as shown in Figure 2 (a). The theoretical model developed in this paper is based on the assumption of a steady-state system including clothing layers, enclosed and boundary air layers.

\subsubsection{Clothing layers}

The thermal insulation of a fabric used to make clothing depends on thermal insulation of fibres and yarns but also on fabric thickness, since the bulk of the thermal resistance is provided by the entrapped air in fabric pores [5]. For fabrics with low porosity the type of fibre and fabric construction may play a role since the ratio of fibre material to the air will increase. The value of thermal insulation can be measured on a hot plate or obtained from the literature $[5$, $27,28]$. In the theoretical model it is assumed that fabric properties are constant and the thickness of the fabric is homogeneous. The porosity and air permeability of the fabric in respect to mass transfer are neglected as forced convection in an enclosed air layer is not considered in the model.

(a)

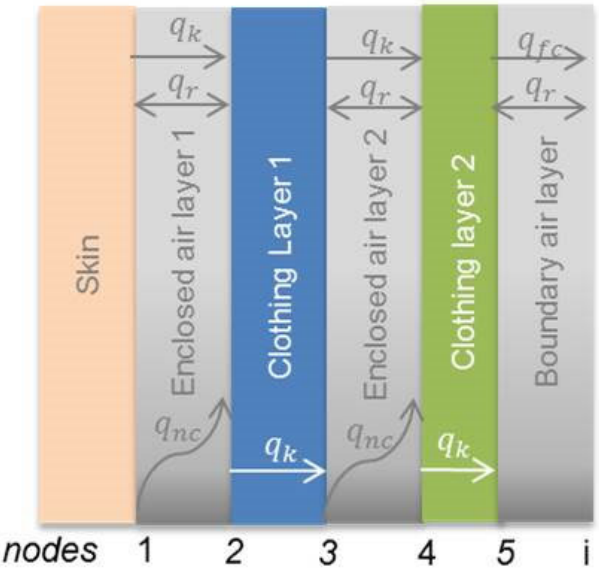

(b)

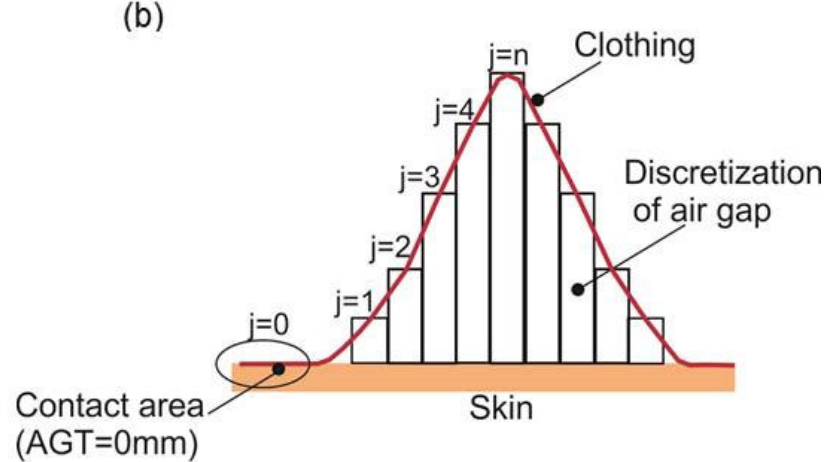

Where,

$q_{k}$ - Conductive heat transfer $q_{n c}$ - Natural convective heat transfer

$q_{r}$ - Radiative heat transfer $q_{f c^{-}}$Forced convective heat transfer AGT: Air gap thickness

Figure 2 Schematic diagram of heat transfer from human body to environment through clothing layers (a), principle of discretization of the enclosed air layer (b) 


\subsubsection{Enclosed air layers}

The thermal resistance of an enclosed air layer depends on its thickness. In the enclosed air layer, heat is transferred through conduction, radiation and natural convection. Forced convection inside the enclosed air layer was not considered in this model. For the surface-to-surface radiation between the skin and different layers of clothing, it is assumed that radiation occurs between two parallel surfaces. To address natural convection, the enclosed air is considered as a rectangular cavity with a wide range of aspect ratios.

\subsubsection{Boundary air layer}

In the boundary air layer, heat is transferred predominantly through convection and radiation. The convective heat transfer consists of forced convection due to the velocity of ambient air and natural convection due to buoyancy effect of heated air on the outer surface of clothing. In the theoretical model, the convective heat transfer in the boundary air layer is calculated using empirical equations. The view factors to calculate radiative heat transfer and coefficients for mixed convection are specific for different body regions.

\subsection{Mathematical formulation of heat transfer in the enclosed air layer}

\subsubsection{Conduction}

The one-dimensional conductive heat transfer in enclosed air layer $\left(\mathrm{q}_{\mathrm{k}_{\mathrm{EAL}}}\right)$ can be defined by the Fourier's law as below:

$$
q_{k_{E A L}}=-k_{E A L} \frac{\left(T_{i}-T_{i+1}\right)}{x_{E A L}}
$$

Where, $T_{i}-T_{i+1}$ : Temperature difference between two adjacent surfaces (K)

$x_{E A L}$ : Thickness of enclosed air layer $(\mathrm{m})$

$k_{E A L}$ : Thermal conductivity of enclosed air $(\mathrm{W} /(\mathrm{mK}))$

The thermal conductivity of the enclosed air $\left(\mathrm{k}_{\mathrm{EAL}}\right)$ is a function of temperature and can be expressed by equation [29]:

$$
\begin{aligned}
& k_{E A L}=0.02624\left(\frac{T_{E A L}}{300}\right)^{0.8646} \\
& T_{E A L}=\frac{T_{i}+T_{i+1}}{2}
\end{aligned}
$$

Where, $\mathrm{T}_{\mathrm{EAL}}$ : Mean temperature of enclosed air layer $(\mathrm{K})$

\subsubsection{Radiation}

The radiation emitted by the surface at a given temperature $(T)$ can be calculated by StefanBoltzmann law as [30]:

$$
q=\sigma \varepsilon T^{4}
$$

Where, $\sigma$ : Stefan-Boltzmann constant equal to $5.670 \times 10^{-8} \mathrm{~W} /\left(\mathrm{m}^{2} \mathrm{k}^{4}\right)$ 
The surface- to- surface radiation between the skin and different clothing layers is calculated by assuming grey planar surfaces. Radiation between two grey planar surfaces confining the enclosed air layer can be given by Kirchhoff's law as below [30]:

$$
\begin{aligned}
& q_{r_{E A L}}=\frac{\sigma\left(T_{i}^{4}-T_{i+1}^{4}\right)}{\frac{1}{\varepsilon_{i}}+\frac{1}{\varepsilon_{i+1}}-1} \\
& h_{r_{E A L}}=\frac{\sigma\left(T_{i}^{2}+T_{i+1}^{2}\right)\left(T_{i}+T_{i+1}\right)}{\frac{1}{\varepsilon_{i}}+\frac{1}{\varepsilon_{i+1}}-1}
\end{aligned}
$$

Where, $q_{r_{E A L}}:$ Radiative heat flux in an enclosed air layer $\mathrm{W} / \mathrm{m}^{2}$

$h_{r_{E A L}}:$ Radiative heat transfer coefficient in an enclosed air layer $\mathrm{W} /\left(\mathrm{m}^{2} K\right)$

$\varepsilon_{i}$ : Emissivity of surface at given node (-)

$T_{i}$ : Temperature of surface at given node $(\mathrm{K})$

The human body and textiles are low-temperature sources (maximal wavelength of $9.5 \mu \mathrm{m}$ ), so emissivity $(\varepsilon)$ of skin and clothing layer is near to unity for many cases [31]. However, it should be measured for special purpose clothing such as aluminized firefighting clothing. In this study, the emissivity of the skin and clothing layer is considered to be 0.95 and 0.9 , respectively.

\subsubsection{Natural convection}

The enclosure formed by skin and clothing layer is approximated by a two-dimensional rectangular shape. In this enclosure, effects of external forces such as forced convection and penetration of ambient air into clothing are neglected. The temperature difference in the enclosure and gravitational forces induce buoyancy effect. Due to this effect, heated and low density air raises upward and cooled and higher density air moves downward. The heat transfer due to this movement of air is called natural convection heat transfer and is defined as:

$$
q_{n c_{E A L}}=h_{n c_{E A L}}\left(T_{i}-T_{i+1}\right)
$$

Heat transfer coefficient for natural convection $\left(h_{n c_{E A L}}\right)$ can be obtained by non-dimensional numbers such as Nusselt number (Nu), Rayleigh number (Ra), Grashof number ( $\mathrm{Gr}$ ) and Prandtl number $(\mathrm{Pr})$. The natural convection in a rectangular cavity depends on aspect ratio. Depending on body part and clothing fit the range of aspect ratio (AR) can vary between 11 to 53 [32]. The empirical equations that cover a wide range of aspect ratios and limitations of Rayleigh number and AR are described in Equation ( 9 ) [25, 26, 33, 34].

$$
h_{n c_{E A L}}=N u \frac{k_{E A L}}{x_{E A L}}
$$

Where,

$h_{n c_{E A L}}:$ Heat transfer coefficient for natural convection $\left(\mathrm{W} /\left(\mathrm{m}^{2} \mathrm{~K}\right)\right)$

$N u$ : Nusselt number (-) 


$$
N u=\left\{\begin{array}{cc}
{\left[1+\left(\frac{0.0665 R a^{\frac{1}{3}}}{1+\left(\frac{9000}{R a}\right)^{1.4}}\right)\right]^{\frac{1}{2}},} & \text { For } R a<10^{6}, A R \geq 40 \\
0.42(R a)^{0.25}(P r)^{0.012}(A R)^{-0.30}, & \text { For } 10^{4}<R a<10^{7}, 10<A R<40 \\
0.22\left(\frac{1}{A R}\right)^{0.09}\left(\frac{P r}{0.2+P r} \cdot R a\right)^{0.28}, & \text { For } 10^{3}<\frac{R a \cdot P r}{0.2+P r}, 2<A R<10
\end{array}\right.
$$

6 Where,

7

8

9

10

11

12

13

14

15

16

17

18

19

20

21

22

23

$$
\begin{gathered}
R a=G r P r \\
G r=\frac{\beta g d T x_{E A L}^{3}}{\vartheta^{2}} \\
\operatorname{Pr}=\frac{\vartheta}{\alpha}
\end{gathered}
$$

Thermal properties of air and other variables at a given temperature can be obtained from empirical equations [29], such as:

$\beta$ : Thermal expansion coefficient of air $(1 / \mathrm{K})$

$$
\beta=\frac{1}{T_{E A L}}
$$

$g$ : Gravitational acceleration equal to $9.83 \mathrm{~m} / \mathrm{s}^{2}$

$R_{a}$ : The specific gas constant equal to $287.05 \mathrm{~J} /(\mathrm{kg} \mathrm{K})$

$P$ : The atmospheric pressure equal to $101325 \mathrm{~Pa}$

$\rho$ : Density of air $\left(\mathrm{kg} / \mathrm{m}^{3}\right)$

$\mu$ : Dynamic viscosity of air (kg/(ms))

$$
\rho=\frac{P}{R_{a} \cdot T_{E A L}}
$$

$$
\mu=\frac{1.458 \times 10^{-6} \cdot T_{E A L}^{1.5}}{T_{E A L}+110.4}
$$

$C_{p}$ : Specific heat of air $(\mathrm{J} /(\mathrm{kgK}))$

$$
c_{p}=1002.5+275 \times 10^{-6}\left(T_{E A L}-200\right)^{2}
$$


$\vartheta:$ Kinematic viscosity of air $\left(\mathrm{m}^{2} / \mathrm{s}\right)$

$$
\vartheta=\frac{\mu}{\rho}
$$

$\alpha:$ Thermal diffusivity of air $\left(\mathrm{m}^{2} / \mathrm{s}\right)$

Nusselt number is the ratio of convective heat transfer to the conductive heat transfer. If the Nusselt number is less than one then the heat transfer in the enclosed air layer is dominated by conduction and radiation $\left(h_{E A L}=h_{k_{E A L}}+h_{r_{E A L}}\right)$. When the Nusselt number is greater than one, the heat transfer is dominated by natural convection and radiation $\left(h_{E A L}=h_{n c_{E A L}}+\right.$ $\left.h_{r_{E A L}}\right)$. Thus, the total heat transfer coefficient for enclosed air layer $\left(\mathrm{h}_{\mathrm{EAL}}\right)$ can be given as:

$$
h_{E A L}=\left(h_{k_{E A L}} \text { or } h_{n c_{E A L}}\right)+h_{r_{E A L}}
$$

\subsection{Mathematical formulation of heat transfer in the boundary air layer}

To develop a clothing model with high spatial resolution, it is necessary to consider the effect of view factor and mixed convection (forced convection along with natural convection) on different body parts. The effect of convection and radiation on different body parts are discussed in section 2.3 .1 and 2.3 .2 respectively:

\subsubsection{Convection}

The convective heat transfer from the human body or outermost clothing layer to the environment depends on natural convection and forced convection due to the movement of ambient air. The convective heat loss by mixed convection can be obtained based on equations (20) and (21) [35]:

Where, $h_{c, \text { mix }_{B A L}}$ : Mixed convective heat transfer coefficient in boundary air layer $\left(\mathrm{W} /\left(\mathrm{m}^{2} \mathrm{~K}\right)\right)$

$$
\begin{aligned}
& q_{c, \text { mix }_{B A L}}=h_{c, \operatorname{mix}_{B A L}}\left(T_{i}-T_{i+1}\right) \\
& h_{c, \text { mix }_{B A L}}=\left(a_{\text {nat }}\left(T_{i}-T_{i+1}\right)^{0.5}+a_{f r c} v_{a}+a_{\text {mix }}\right)^{0.5}
\end{aligned}
$$

$\left(T_{i}-T_{i+1}\right)$ : Temperature difference between outermost clothing layer (skin temperature for nude body) and ambient air (K) $v_{a}:$ Speed of ambient air $(\mathrm{m} / \mathrm{s})$

$a_{\text {nat }}$ : Coefficient for the natural convection (-) $a_{f r c}$ : Coefficient for the forced convection (-) $a_{\text {mix }}$ : Coefficient for the mixed convection (-) The derived values of $a_{n a t}, a_{f r c}$, and $a_{m i x}$ for different body segments are described in Table 1 [35].

\subsubsection{Radiation}

The radiative heat transfer from outermost clothing layer to the environment can be calculated as follows:

$$
q_{r_{B A L}}=\sigma \varepsilon \theta\left(T_{i}^{4}-T_{i+1}^{4}\right)
$$




$$
h_{r_{B A L}}=\sigma \varepsilon \theta\left(T_{i}^{2}+T_{i+1}^{2}\right)\left(T_{i}+T_{i+1}\right)
$$

Where, $h_{r_{B A L}}$ : Radiative heat transfer coefficient in boundary air layer $\left(\mathrm{W} /\left(\mathrm{m}^{2} K\right)\right)$

$T_{i}$ : Temperature of outermost clothing (skin temperature for nude body) (K)

$T_{i+1}$ : Mean radiant temperature of ambient air $(\mathrm{K})$

$\theta$ : View factor between body segment and environment (-)

The view factors between three-dimensional human body segment and environment were investigated by Kubaha et al. [36] and presented in Table 1. For the simulations of radiative heat transfer from a heated cylinder in the validation study, the coefficients of the anterior and posterior thorax have been used.

Table 1 Parameters for convective heat transfer coefficient and view factor $(\theta)[35,36]$

\begin{tabular}{|c|c|c|c|c|c|c|c|}
\hline \multirow{2}{*}{ Body segment } & \multicolumn{3}{|c|}{ Coefficient } & \multicolumn{4}{|c|}{ View factor $(\theta)$} \\
\hline & $a_{\text {nat }}$ & $a_{f r c}$ & $a_{\text {mix }}$ & Anterior & Posterior & Inferior & Exterior \\
\hline Head & 3.000 & 113.00 & -5.650 & 0.9869 & 0.9643 & $\mathrm{n} / \mathrm{a}$ & $\mathrm{n} / \mathrm{a}$ \\
\hline Face & 3.000 & 113.00 & -5.650 & 0.8417 & 0.8909 & $\mathrm{n} / \mathrm{a}$ & $\mathrm{n} / \mathrm{a}$ \\
\hline Neck & 1.600 & 130.00 & -6.500 & 0.7792 & 0.9433 & 0.8659 & $\mathrm{n} / \mathrm{a}$ \\
\hline Shoulders & 5.900 & 216.00 & -10.800 & 0.9048 & $\mathrm{n} / \mathrm{a}$ & $\mathrm{n} / \mathrm{a}$ & $\mathrm{n} / \mathrm{a}$ \\
\hline Thorax & 0.500 & 180.00 & -7.400 & 0.9314 & 0.9590 & 0.4408 & $\mathrm{n} / \mathrm{a}$ \\
\hline Abdomen & 1.200 & 180.00 & -9.000 & 0.8923 & 0.8886 & 0.6323 & $\mathrm{n} / \mathrm{a}$ \\
\hline Upper arms & 8.270 & 216.02 & -10.801 & 0.7546 & 0.9268 & 0.3356 & 0.9821 \\
\hline Lower arms & 8.270 & 216.02 & -10.801 & 0.8774 & 0.9639 & 0.5065 & 0.9967 \\
\hline Hands & 8.270 & 216.02 & -10.801 & 0.8835 & 0.3801 & $\mathrm{n} / \mathrm{a}$ & $\mathrm{n} / \mathrm{a}$ \\
\hline Upper legs & 5.300 & 220.00 & -11.000 & 0.8761 & 0.9374 & 0.4693 & 0.8793 \\
\hline Lower legs & 5.300 & 220.00 & -11.000 & 0.9282 & 0.9393 & 0.7264 & 0.9800 \\
\hline Feet & 6.800 & 210.00 & -10.500 & 0.8602 & 0.8955 & $\mathrm{n} / \mathrm{a}$ & $\mathrm{n} / \mathrm{a}$ \\
\hline
\end{tabular}

13

The total heat transfer coefficient for boundary air layer $h_{B A L}$ can be then defined as:

$$
h_{B A L}=\left(h_{c, m_{i x}}+h_{r_{B A L}}\right) \cdot f_{c l}
$$

Where, $f_{c l}$ : Clothing area factor $\left(\mathrm{m}^{2}\right)$

As shown in Figure 2 (b), due to folds and the enclosed air gap, the surface area of the clothing is greater than the surface area of skin, unlike in the planar surface system as shown in Figure 2 (a). To account for this difference between surfaces of inflow and outflow of heat in the one-dimensional clothing model the clothing area factor $\left(f_{c l}\right)$ has been used [27]. 


$$
f_{c l}=\frac{A_{c l}}{A_{s k}}
$$

Where, $A_{c l}$ : Surface area of the clothing $\left(\mathrm{m}^{2}\right)$

$A_{s k}:$ Surface area of the skin $\left(\mathrm{m}^{2}\right)$

\subsection{Mathematical formulation of heat transfer in heterogeneous air gaps}

To obtain the heat flux for a heterogeneous enclosed air layer, it can be discretized into smaller elements $\left(w_{j}\right)$ as shown in Figure $2(b)$, where each small discretized element can be considered as a homogeneous air gap. Applying Equations (20) and (25) for each small homogeneous section and then integrating them results in an equivalent thermal heat transfer coefficient $\left(h_{E A L_{e q}}\right.$ and $\left.h_{B A L_{e q}}\right)$ for the heterogeneous enclosed and boundary air layers.

The mathematical formulation to calculate heat transfer coefficient for heterogeneous enclosed air layer can be given as follows:

$$
h_{E A L_{e q}}=\sum_{j=1}^{n} h_{E A L_{j}} w_{j}
$$

At each discretized element $\left(\mathrm{w}_{\mathrm{j}}\right)$, the temperature of the outermost clothing layer should be different, so the equivalent heat transfer coefficient for the boundary air layer can be given as follows:

$$
h_{B A L_{e q}}=\sum_{j=1}^{n} h_{B A L_{j}} w_{j}
$$

Where, $w_{j}$ : Discretized element (percentage of skin surface area with a certain air gap thickness out of total skin surface area of the considered region)

$h_{E A L_{j}}$ : Heat transfer coefficient for enclosed air layer for $j^{\text {th }}$ element $\left(\mathrm{W} /\left(\mathrm{m}^{2} \mathrm{~K}\right)\right)$ $h_{B A L_{j}}$ : Heat transfer coefficient for boundary air layer for $j^{\text {th }}$ element $\left(\mathrm{W} /\left(\mathrm{m}^{2} \mathrm{~K}\right)\right)$ j: Element number (-)

$n$ : Total number of elements (-)

Detailed data describing the discretized elements $\left(w_{j}\right)$ of enclosed air layer can be obtained from the 3D body scanning method [10], or can be approximated for body regions from the air gap thickness model developed by Psikuta et al. [24].

\subsection{Total heat flux}

From Equations (26-27) the total heat transfer coefficient for the human-clothing-environment system $\left(h_{\text {total }}\right)$ can be calculated as follows:

$$
\frac{1}{h_{\text {total }}}=\frac{1}{h_{E A L_{e q}}}+\frac{1}{h_{c l}}+\frac{1}{h_{B A L_{e q}}}
$$

Where the heat transfer coefficient for clothing layers $\left(h_{c l}\right)$ can be obtained from the thickness of the fabric [5] or from a hot plate measurement [27]. For common fibres the heat transfer coefficient is available in literature in terms of thermal insulation $\left(R_{c t}\right)$ [27]. 
The temperature distribution at each node $(i)$ can be calculated as follows [6]:

$$
T_{i}=T_{\text {skin }}-\left(T_{\text {skin }}-T_{\text {amb }}\right) \frac{h_{\text {total }}}{h_{\rightarrow i}}
$$

Where, $q_{\text {total }}$ : Total heat flux from skin to the environment $\left(\mathrm{W} / \mathrm{m}^{2}\right)$

$h_{\text {total }}$ : Total heat transfer coefficient from the skin to the environment $\left(\mathrm{W} /\left(\mathrm{m}^{2} \mathrm{~K}\right)\right)$ $h_{\rightarrow i}$ : Heat transfer coefficient up to the $i^{\text {th }}$ node $\left(\mathrm{W} /\left(\mathrm{m}^{2} \mathrm{~K}\right)\right)$ $T_{\text {skin }}$ : Temperature of skin (K) $T_{a m b}:$ Temperature of ambient air(K)

\subsection{Clothing model validation}

\subsubsection{Validation strategy}

To validate the theoretical clothing model, the simulated data were systematically compared with experimental measurements using cases with increasing level of geometrical and component complexities. First, the theoretical model was validated for the homogeneous enclosed air layer for different ambient conditions and air gap thicknesses around a thermal cylinder. In the second step, the model was compared to the measurement results for spatially heterogeneous but regular enclosed air layers around a thermal cylinder. Finally, the applicability of theoretical clothing model was tested on an anatomically shaped thermal manikin with heterogeneous and irregular air layers representing the realistic scenario of enclosed air layer around the human body. In these validation tests both single-layer and multi-layer clothing ensembles were used with the latter one posing a further challenge to the model.

The accuracy of simulation depends on the accuracy of input data. To precisely predict the heat flux through heterogeneous air gaps, it can be discretised into several elements using $3 D$ scanning. However, in case when 3D scanning method is not available or applicable (for the case of multi-layer garments), enclosed air layer can be divided into at least two elements using a local air gap thickness and contact area regression model developed by Psikuta et al. [24] (based on 3D scanning of 51 casual and protective garments): (1 element) contact area (between clothing and skin), (2 element) average air gap thickness (non-contact area), as shown in 2 (b). The local air gap thickness and contact area model provides the distribution of contact area and air gap for different body parts (locally), based on ease allowance, which is easy to obtain based on circumference measurement of the body and the garment [24]. Both approaches based on regression model or 3D scanning are presented and validated in the present study.

\subsubsection{Homogeneous enclosed air layer around a heated cylinder}

In the studies reported by Mert et al. and Richards et al. , the heat flux from a thermal cylinder covered by clothing with a homogeneous air gap to the environment was measured [15, 
1 37]. The cylinder was placed vertically and had diameter and length of $0.3 \mathrm{~m}$ and $0.46 \mathrm{~m}$, re2 spectively [38-40]. The thermal cylinder was covered with a tight fabric layer which acted as

3 an artificial skin and was assumed to allow no air layer trapped underneath (layer 1). The 4 second layer of fabric was placed around the thermal cylinder at a known predefined dis5 tance (layer 2). The thickness of the enclosed air layer, ambient conditions, and properties of 6 the fabric are listed in Table 2. For the simulation of heat transfer in the boundary air layer 7 from the thermal cylinder, the coefficient of the thorax has been considered from Table 1.

8 Table 2. Experimental parameters from the studies of Mert et al. [24] and Richards et al. [35]

\begin{tabular}{|c|c|c|c|c|c|c|c|c|}
\hline \multirow{3}{*}{$\begin{array}{c}\text { Case } \\
\text { no. }\end{array}$} & \multirow{2}{*}{\multicolumn{4}{|c|}{ Ambient conditions }} & & \multirow{3}{*}{$\begin{array}{l}\text { Thickness } \\
\text { of } \\
\text { enclosed } \\
\text { air layer } \\
(\mathrm{mm})\end{array}$} & \multicolumn{2}{|c|}{ Fabric properties } \\
\hline & & & & & & & \multirow{2}{*}{$\begin{array}{l}\text { Layer1 } \\
\mathrm{R}_{\mathrm{ct}}\left(\frac{\mathrm{m}^{2} \mathrm{~K}}{\mathrm{~W}}\right)\end{array}$} & \multirow{2}{*}{$\begin{array}{l}\text { Layer2 } \\
\mathrm{R}_{\mathrm{ct}}\left(\frac{\mathrm{m}^{2} \mathrm{~K}}{\mathrm{~W}}\right)\end{array}$} \\
\hline & $\begin{array}{l}\mathrm{T}_{\text {skin }} \\
\left({ }^{\circ} \mathrm{C}\right)\end{array}$ & $\begin{array}{l}\mathrm{T}_{\mathrm{amb}} \\
\left({ }^{\circ} \mathrm{C}\right)\end{array}$ & $\begin{array}{c}\mathrm{v}_{\mathrm{a}} \\
(\mathrm{m} / \mathrm{s})\end{array}$ & $\begin{array}{l}\mathrm{RH} \\
(\%)\end{array}$ & $\begin{array}{l}\text { fcl } \\
(-)\end{array}$ & & & \\
\hline 1 & 35 & 20 & 0.2 & 50 & 1.33 & 50 & 0.012 & 0.012 \\
\hline 2 & 35 & 20 & 0.2 & 50 & 1.20 & 30 & 0.012 & 0.012 \\
\hline 3 & 35 & 20 & 0.2 & 50 & 1.07 & 10 & 0.012 & 0.012 \\
\hline 4 & 35 & 20 & 1.0 & 65 & 1.05 & 8 & 0.014 & 0.023 \\
\hline 5 & 35 & 20 & 1.0 & 65 & 1.05 & 8 & 0.014 & 0.007 \\
\hline 6 & 35 & 10 & 1.0 & 65 & 1.05 & 8 & 0.014 & 0.023 \\
\hline 7 & 35 & 10 & 1.0 & 65 & 1.05 & 8 & 0.014 & 0.007 \\
\hline
\end{tabular}

\subsubsection{Heterogeneous enclosed air layer around a heated cylinder}

To investigate the heat transfer for the heterogeneous regular enclosed air layer, Mert et al. [15] performed several experiments on the heated cylinder with different configurations and size of the folds. The size and configuration of folds were selected based on 3D scanning of 18 casual garments and more than 300 different folds. The experimental parameters were as described in Table 3 and graphical representations of the folds are described in Figure 3.

Table 3 Experimental parameters from the study of Mert et al. [15]

\begin{tabular}{|c|c|c|c|c|c|c|c|c|c|}
\hline \multirow{3}{*}{$\begin{array}{l}\text { Case } \\
\text { no. }\end{array}$} & \multirow{2}{*}{\multicolumn{5}{|c|}{ Ambient conditions }} & \multirow{2}{*}{\multicolumn{2}{|c|}{$\begin{array}{c}\text { Enclosed air } \\
\text { layer }\end{array}$}} & \multicolumn{2}{|c|}{ Fabric properties } \\
\hline & & & & & & & & \multirow{2}{*}{$\begin{array}{c}\text { Layer1 } \\
\mathrm{R}_{\mathrm{ct}}\left(\frac{\mathrm{m}^{2} \mathrm{~K}}{\mathrm{~W}}\right)\end{array}$} & \multirow{2}{*}{$\begin{array}{r}\text { Layer2 } \\
\mathrm{R}_{\mathrm{ct}}\left(\frac{\mathrm{m}^{2} \mathrm{~K}}{\mathrm{~W}}\right)\end{array}$} \\
\hline & $\begin{array}{l}\mathrm{T}_{\text {skin }} \\
\left({ }^{\circ} \mathrm{C}\right)\end{array}$ & $\begin{array}{l}\mathrm{T}_{\mathrm{amb}} \\
\left({ }^{\circ} \mathrm{C}\right)\end{array}$ & $\begin{array}{c}\mathrm{v}_{\mathrm{a}} \\
(\mathrm{m} / \mathrm{s})\end{array}$ & $\begin{array}{l}\mathrm{RH} \\
(\%)\end{array}$ & $\begin{array}{l}\text { fcl } \\
(-)\end{array}$ & $\begin{array}{l}\mathrm{CA} \\
\left(\mathrm{w}_{1}\right) \\
(\%)\end{array}$ & $\begin{array}{l}\text { AGT* }^{*} \\
\left(\mathrm{w}_{2}\right) \\
(\mathrm{mm})\end{array}$ & & \\
\hline 8 & 35 & 20 & 0.2 & 50 & 1.15 & $3 \%$ & 23 & 0.012 & 0.012 \\
\hline 9 & 35 & 20 & 0.2 & 50 & 1.10 & $3 \%$ & 16 & 0.012 & 0.012 \\
\hline 10 & 35 & 20 & 0.2 & 50 & 1.04 & $11 \%$ & 6 & 0.012 & 0.012 \\
\hline 11 & 35 & 20 & 0.2 & 50 & 1.10 & $8 \%$ & 15 & 0.012 & 0.012 \\
\hline
\end{tabular}




\begin{tabular}{llllllllll}
12 & 35 & 20 & 0.2 & 50 & 1.08 & $19 \%$ & 12 & 0.012 & 0.012 \\
13 & 35 & 20 & 0.2 & 50 & 1.05 & $42 \%$ & 8 & 0.012 & 0.012 \\
14 & 35 & 20 & 0.2 & 50 & 1.03 & $67 \%$ & 5 & 0.012 & 0.012 \\
\hline
\end{tabular}

CA: Contact Area, AGT: total Air Gap Thickness, $\mathrm{AGT}^{*}=$ Air gap thickness for remaining surface (not including $\mathrm{CA})$, where $\left[* \mathrm{w}_{2}=\right.$ Mean $\left.A G T /\left(1-\left(\mathrm{w}_{1} / 100\right)\right)\right]$

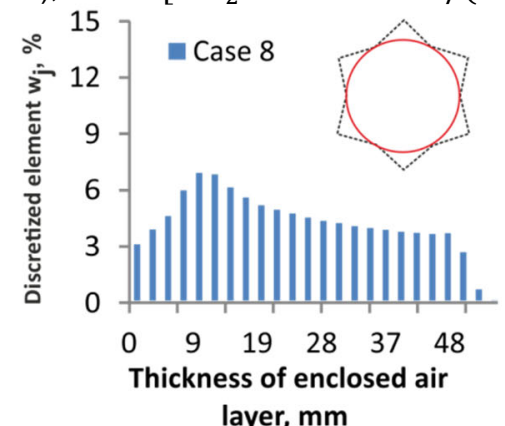

layer, $\mathrm{mm}$
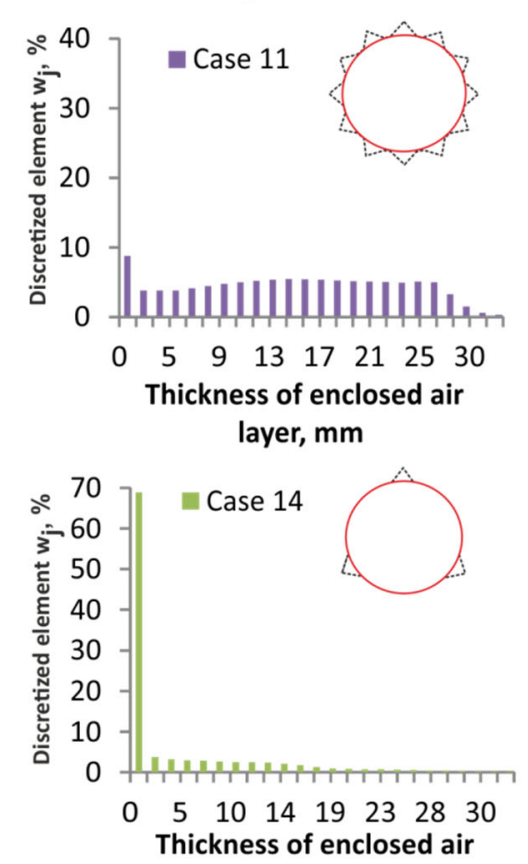

layer, $\mathrm{mm}$

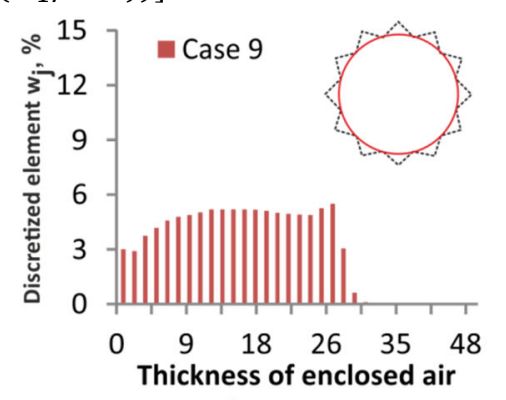

layer, $\mathrm{mm}$

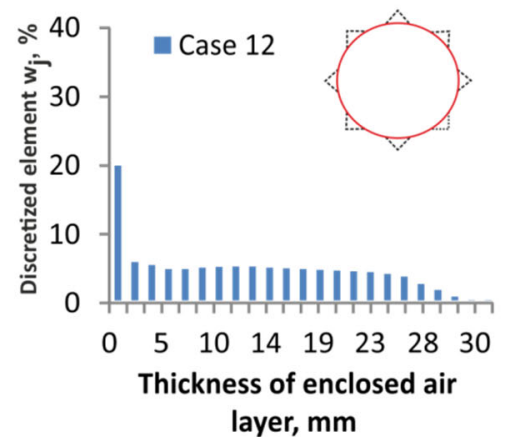

layer, mm

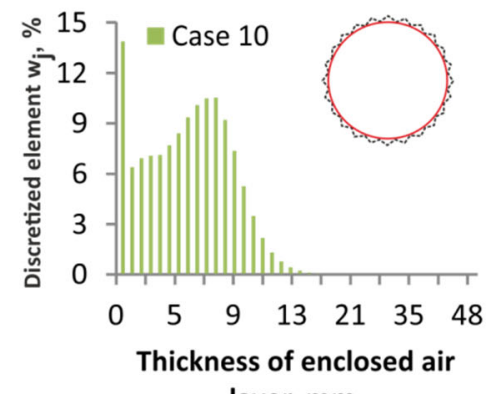

layer, $\mathrm{mm}$

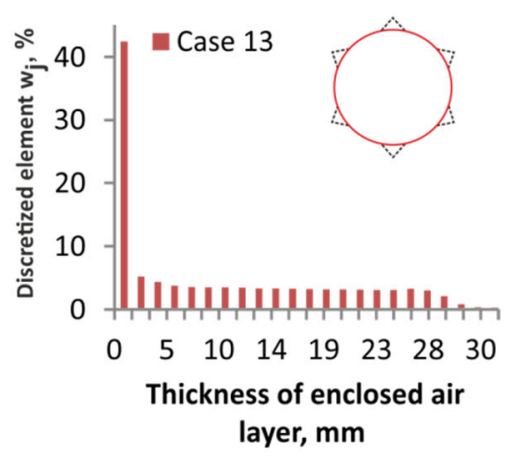

Figure 3 Graphical presentation of discretized elements $\left(\mathrm{w}_{\mathrm{j}}\right.$, over air gap thickness with an increment of $2 \mathrm{~mm}$ for different configurations of folds according to Mert et al. [15]

\subsubsection{Heterogeneous enclosed air layer around thermal manikin in single-layer cloth- ing ensemble}

To validate the theoretical model presented in this paper, measurements were performed on an anatomically shaped thermal manikin [41-43] with a single-layer garment representing a long-sleeve T-shirt. The data regarding the thickness of the enclosed air layer were obtained from a 3D scan method for single-layer garment [10]. To generate the different configurations of the folds, the T-shirt was measured while loosely hanging around the waistline (Figure 4 (a) and (b)), and while being bound at waist simulating the T-shirt being tucked in the lower body garment (Figure 4(c) and (d)).Both cases presented in Figure 4 have a distinct distribution of 
1 air gap and contact area. The experimental conditions and material properties of the fabric are

2 listed in Table 4.

3
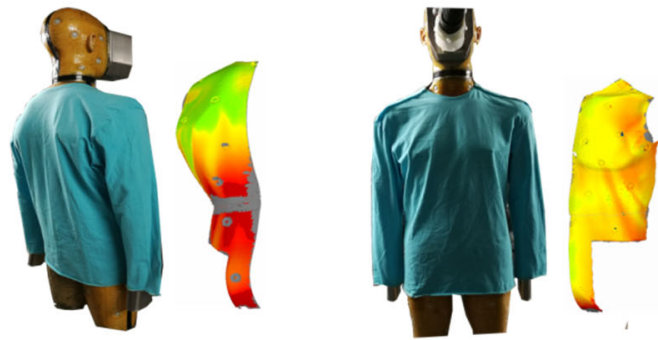

$\begin{array}{llllllllll}-5 & 0 & 25 & 50 & 75 & 100 & 125 & 150 & 200\end{array}$ contact area

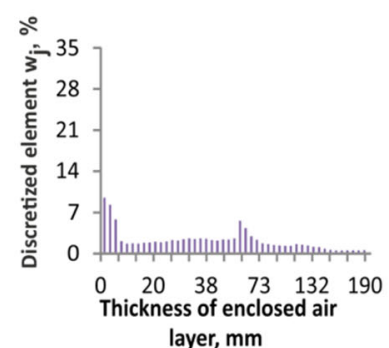
layer, $\mathrm{mm}$

(a)

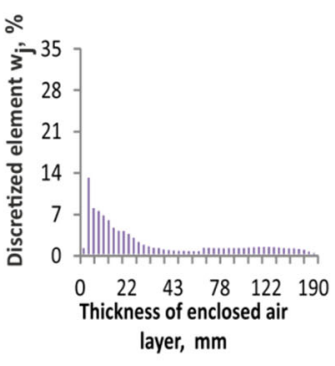

(b)
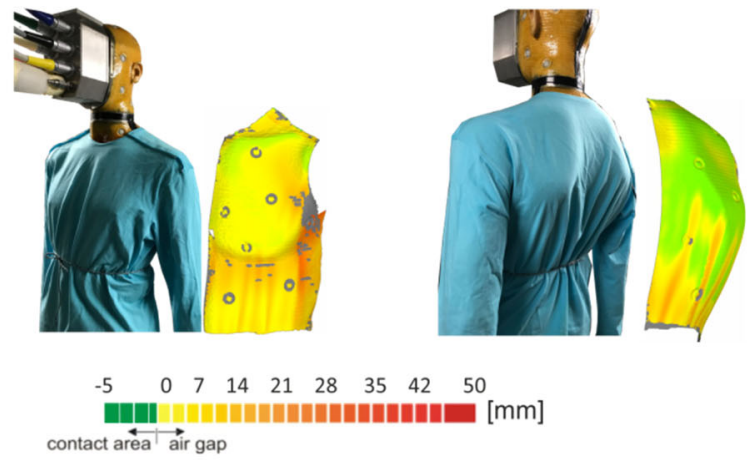

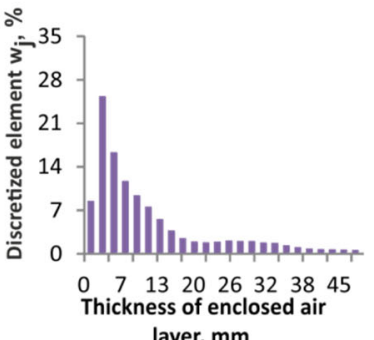

layer, $\mathrm{mm}$

(c)

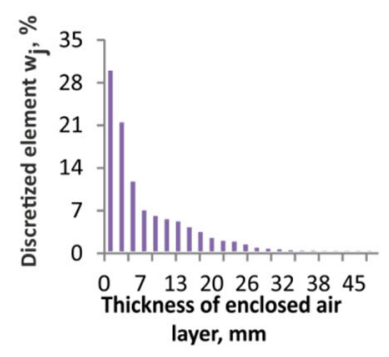

(d)

Figure 4 Thermal manikin wearing loose-fitted T-shirt and the air gap distribution discretized

6 with an increment of $2 \mathrm{~mm}$ obtained using 3D scanning technique for back and buttocks [case 15] (a), and chest and abdomen [case 16] (b) in loosely hanging case, and for chest [cases 


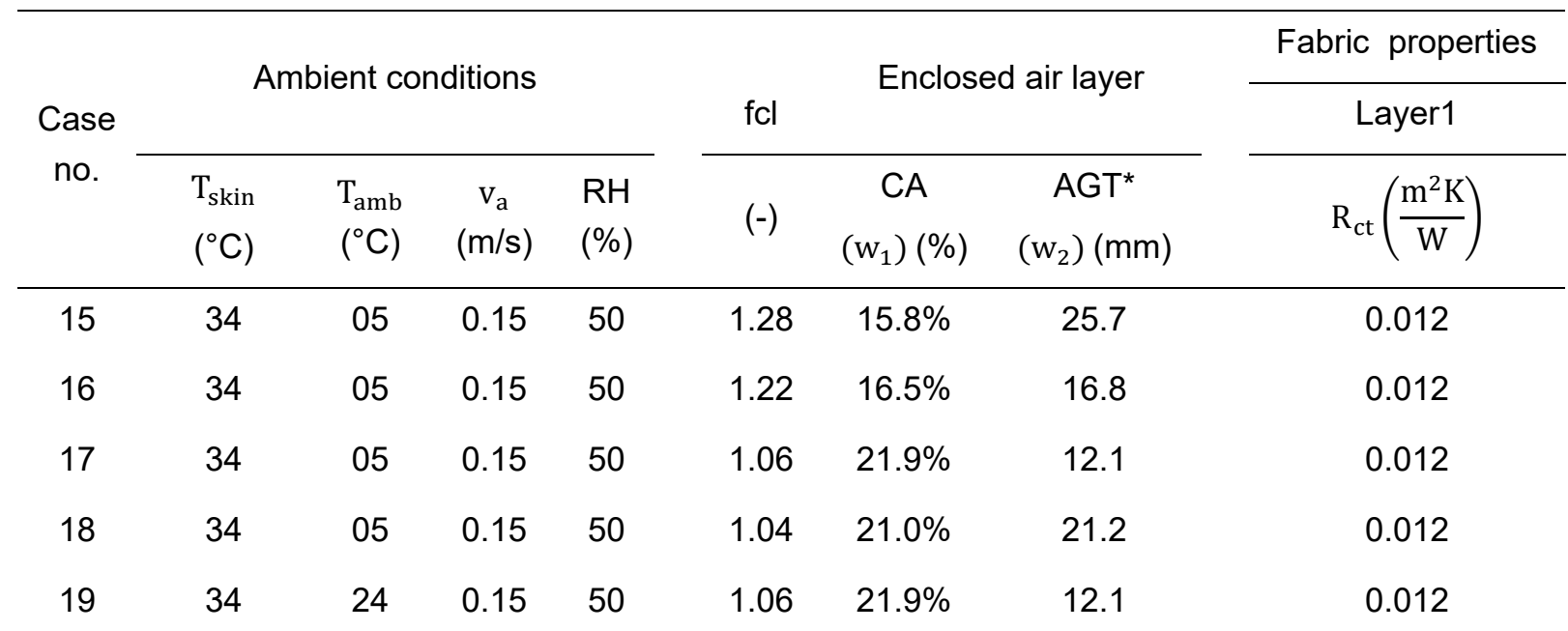

\subsubsection{Heterogeneous enclosed air layer around thermal manikin in multi-layer clothing ensemble}

7 For multi-layer clothing including four individual layers it was not possible to obtain the air

8 gap thickness distribution using the 3D scanning technique since 3D scanner can capture

9 only the shape of the outermost layer. To obtain this data, the air gap model developed by

10 Psikuta et al. [24] was used as well as the findings by Mark [44] describing the confinement 11 of the inner layer by the outer layer. The obtained data of air gap distribution through the air 12 gap model are listed in Table 5 and the material properties and experimental conditions in 13 Table 6.

14 The multi-layer clothing ensemble consisted of fabric skin (layer 1), underwear (layer 2), in15 sulation jacket (layer 3 ), and outer jacket (layer 4). It is assumed that there is no air gap $16 \quad($ AGT $=0 \mathrm{~mm})$ between the skin and fabric skin layer. Table 5 presents the percentage of area $\left(\left(\mathrm{w}_{1}\right), \%\right)$ with $0 \mathrm{~mm}$ of air gap and the average air gap thickness for the remaining area $\left(\left(\mathrm{w}_{2}\right), \mathrm{mm}\right)$ predicted by the air gap thickness and contact area model [24]. Hence, the air gap of the enclosed air layer can be discretized into two elements $\left(w_{1}\right.$ and $\left.w_{2}\right)$. The value of $\mathrm{w}_{2}$ can be calculated as:

$$
w_{2}=100-w_{1}
$$


2 Table 5 Distribution of air gap between different layers of clothing obtained from local air gap thickness model developed by Psikuta et al. [24]

\begin{tabular}{|c|c|c|c|c|c|c|c|c|c|c|}
\hline \multirow{2}{*}{\multicolumn{2}{|c|}{ Body segment }} & \multicolumn{4}{|c|}{$\begin{array}{l}\text { Enclosed air layer } \\
\text { Layer 1-Layer } 2\end{array}$} & \multicolumn{2}{|c|}{$\begin{array}{l}\text { Enclosed air layer } \\
\text { Layer 2-Layer } 3\end{array}$} & \multicolumn{3}{|c|}{$\begin{array}{l}\text { Enclosed air layer } \\
\text { Layer 3-Layer } 4\end{array}$} \\
\hline & & \multicolumn{2}{|c|}{$\begin{array}{c}\mathrm{CA} \\
\left(\mathrm{w}_{1}\right)(\%)\end{array}$} & \multicolumn{2}{|c|}{$\begin{array}{c}\text { AGT } \\
\left(\mathrm{w}_{2}\right)(\mathrm{mm})\end{array}$} & $\begin{array}{c}\text { CA } \\
\left(w_{1}\right)(\%)\end{array}$ & $\begin{array}{c}\text { AGT } \\
\left(w_{2}\right)(\mathrm{mm})\end{array}$ & $\begin{array}{c}\text { CA } \\
\left(w_{1}\right)(\%)\end{array}$ & & $\begin{array}{c}\text { AGT } \\
\left(\mathrm{w}_{2}\right)(\mathrm{mm})\end{array}$ \\
\hline \multicolumn{2}{|c|}{ Chest } & \multicolumn{2}{|c|}{$24.0 \%$} & \multicolumn{2}{|c|}{8.7} & $13.3 \%$ & 4.9 & \multicolumn{2}{|c|}{$10.4 \%$} & 0.7 \\
\hline \multicolumn{2}{|c|}{ Back } & \multicolumn{2}{|c|}{$21.3 \%$} & \multicolumn{2}{|c|}{17.8} & $13.3 \%$ & 9.1 & \multicolumn{2}{|c|}{$11.1 \%$} & 1.8 \\
\hline \multicolumn{2}{|c|}{ Upper arm } & \multicolumn{2}{|c|}{$16.2 \%$} & \multicolumn{2}{|c|}{12.8} & $14.5 \%$ & 1.1 & \multicolumn{2}{|c|}{$11.1 \%$} & 0.8 \\
\hline \multicolumn{11}{|c|}{$\begin{array}{l}\text { CA: Contact Area, AGT: total Air Gap Thickness, } \text { AGT }^{*}=\text { Air gap th } \\
\text { CA), where }\left[* \mathrm{w}_{2}=\text { Mean AGT } /\left(1-\left(\mathrm{w}_{1} / 100\right)\right)\right]\end{array}$} \\
\hline \multirow{2}{*}{\multicolumn{6}{|c|}{$\begin{array}{l}\text { Ambient condi- } \\
\text { tions }\end{array}$}} & & \multicolumn{4}{|c|}{ Fabric properties } \\
\hline & & & & & & Body & Layer 1 & Layer 2 & Layer 3 & Layer 4 \\
\hline no. & $\begin{array}{l}\mathrm{T}_{\text {skin }} \\
\left({ }^{\circ} \mathrm{C}\right)\end{array}$ & $\begin{array}{l}\mathrm{T}_{\mathrm{amb}} \\
\left({ }^{\circ} \mathrm{C}\right)\end{array}$ & $\begin{array}{c}\mathrm{v}_{\mathrm{a}} \\
(\mathrm{m} / \mathrm{s})\end{array}$ & $\begin{array}{l}\mathrm{RH} \\
(\%)\end{array}$ & fcl & segment & $\mathrm{R}_{\mathrm{ct}}\left(\frac{\mathrm{m}^{2} \mathrm{~K}}{\mathrm{~W}}\right)$ & $\mathrm{R}_{\mathrm{ct}}\left(\frac{\mathrm{m}^{2} \mathrm{~K}}{\mathrm{~W}}\right)$ & $\mathrm{R}_{\mathrm{ct}}\left(\frac{\mathrm{m}^{2} \mathrm{~K}}{\mathrm{~W}}\right)$ & $\mathrm{R}_{\mathrm{ct}}\left(\frac{\mathrm{m}^{2} \mathrm{~K}}{\mathrm{~W}}\right)$ \\
\hline 21 & 34 & -5 & 0.15 & 30 & 1.08 & Chest & 0.017 & 0.0337 & 0.0337 & 0.0105 \\
\hline 22 & 34 & -5 & 0.15 & 30 & 1.16 & Back & 0.017 & 0.0337 & 0.0337 & 0.0105 \\
\hline 23 & 34 & -5 & 0.15 & 30 & 1.076 & Upper arm & 0.017 & 0.0337 & 0.0337 & 0.0105 \\
\hline 24 & 34 & -10 & 0.15 & 30 & 1.076 & Chest & 0017 & 0.0337 & 0.0337 & 0.0105 \\
\hline 25 & 34 & -10 & 0.15 & 30 & 1.158 & Back & 0.017 & 0.0337 & 0.0337 & 0.0105 \\
\hline 26 & 34 & -10 & 0.15 & 30 & 1.076 & Upper arm & 0.017 & 0.0337 & 0.0337 & 0.0105 \\
\hline
\end{tabular}

\subsection{Parametric study}

9 The parametric study has been done to understand the effect of various parameters on total

10 heat transfer and different heat transfer mechanisms. The following parameters were ana-

11 lysed over a wide range of thicknesses for enclosed air layer:

- The effect of ambient temperature on total heat flux and on different heat transfer mechanisms in an enclosed air layer were analysed for three conditions $\left(0^{\circ} \mathrm{C}, 10^{\circ} \mathrm{C}\right.$ and $\left.22^{\circ} \mathrm{C}\right)$.

- The effect of ambient air velocity on total heat flux and different heat transfer mechanisms in an enclosed air layer was analysed for three velocity magnitudes $\left(v_{a}=0.2 \mathrm{~m} / \mathrm{s}, 1 \mathrm{~m} / \mathrm{s}\right.$, and $4 \mathrm{~m} / \mathrm{s}$ ). 
- The effect of fabric emissivity on total heat flux and different heat transfer mechanisms in an enclosed air layer were analysed for three emission coefficients $(\varepsilon=0.05,0.50$ and 0.95).

- The effect of contact area (between skin and fabric) on total heat flux and different heat transfer mechanisms in an enclosed air layer were analysed for three values $(10 \%, 20 \%$ and $40 \%)$.

The ambient temperature of $22^{\circ} \mathrm{C}$, the skin temperature of $35^{\circ} \mathrm{C}$, the ambient air velocity of $0.2 \mathrm{~m} / \mathrm{s}$, the emissivity of skin and fabric of 0.95 and 0.90 , respectively, homogeneous air gap thickness and the thermal insulation of fabric (around the thermal cylinder at a given distance) of $0.012 \mathrm{~m}^{2} \mathrm{~K} / \mathrm{W}$ as a base case for all parametric studies were used unless differently specified.

\subsection{Statistical analysis}

To validate the theoretical clothing model presented in this paper, and to compare the results obtained with the experimentally measured data, the relative error (RE) is calculated (Eq. 32 ), using the experimentally measured value as a reference value:

$$
\% \text { Relative error }(R E)=\frac{\text { Experimental data-Modelling data }}{\text { Experimental data }} \times 100 \%
$$

The deviation of experimentally measured data, and data obtained through the theoretical clothing model were calculated using following formula:

$$
\begin{aligned}
& \text { Standard Deviation }(S D)=\sqrt{\frac{\sum(x-\bar{x})^{2}}{(j-1)}} \\
& \text { Coefficient of variation }(C V)=\frac{S D}{\bar{x}} \times 100 \%
\end{aligned}
$$

Where $\bar{x}$ : mean value of sample data

$$
j \text { : sample size. }
$$

The SD in experimental data resulted from the repetition of the measurement, while the SD in theoretically computed data resulted from the deviation in input data (e.g. variation in measured air gap thickness due to repetitions in 3D scanning). 


\section{Results}

2

3 Figure 5 presents the comparison between theoretically simulated and experimentally meas-

4 ured values of heat flux for all validation cases grouped in four levels of validation complexity.

5 The description of ambient conditions and material properties for each individual case is

6 given in Table 2-6.

(a)

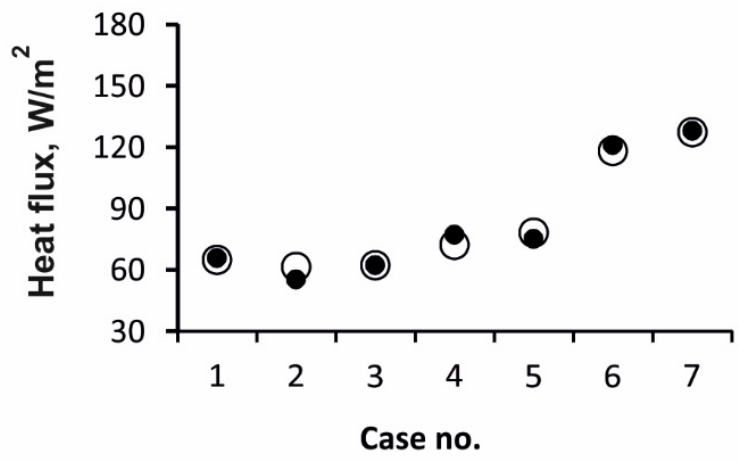

(c)

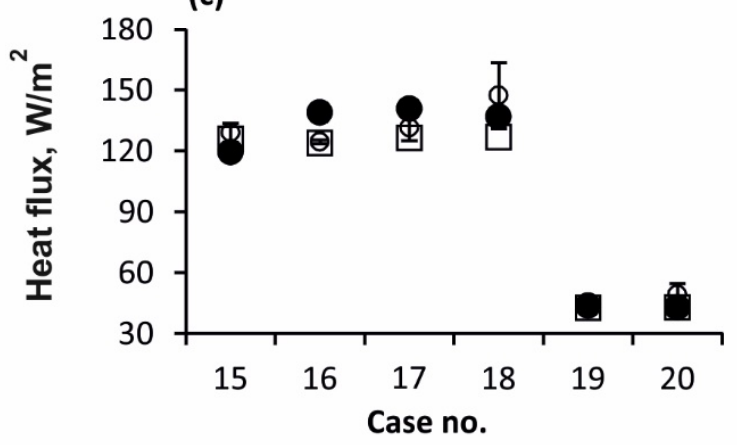

(b)

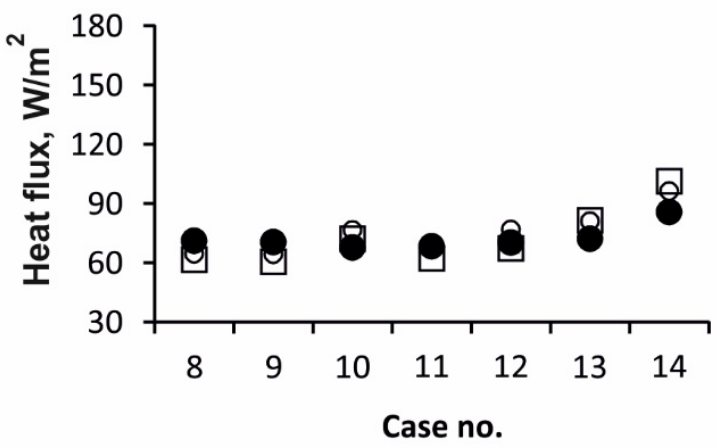

(d)

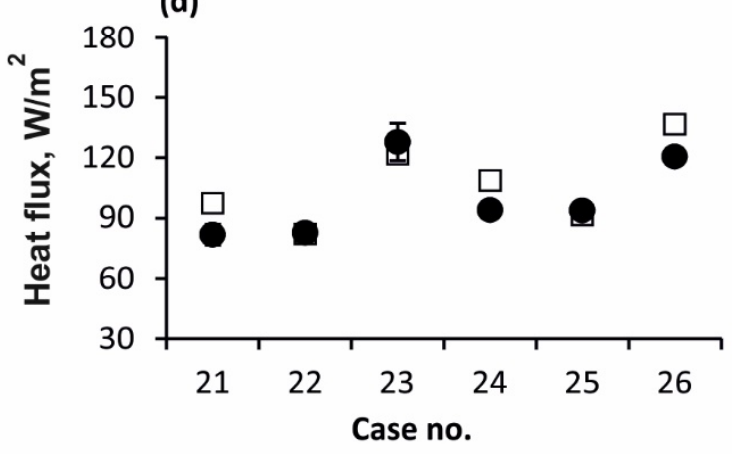

${ }^{*}:$ When air gap thickness is discretized into only two elements such as contact area

Experimental and mean air gap thickness for the remaining surface area

OTheoretical

口Theoretical*

Figure 5 Heat fluxes measured using thermal devices and climatic chambers, and obtained data from the theoretical clothing model for homogeneous (a), heterogeneous regular enclosed air layer around a thermal cylinder (b), heterogeneous irregular enclosed air layer around the thermal manikin dressed in a single-layer garment (c), and heterogeneous irregu-

lar enclosed air layer around thermal manikin dressed in a multi-layer ensemble (d)

Figure 6 presents results from the developed model: the effect of various parameters such as ambient temperature, fabric emissivity, ambient air velocity, and the contact area between skin and fabric, on total heat flux, and their effect on different heat transfer mechanisms. 
Left
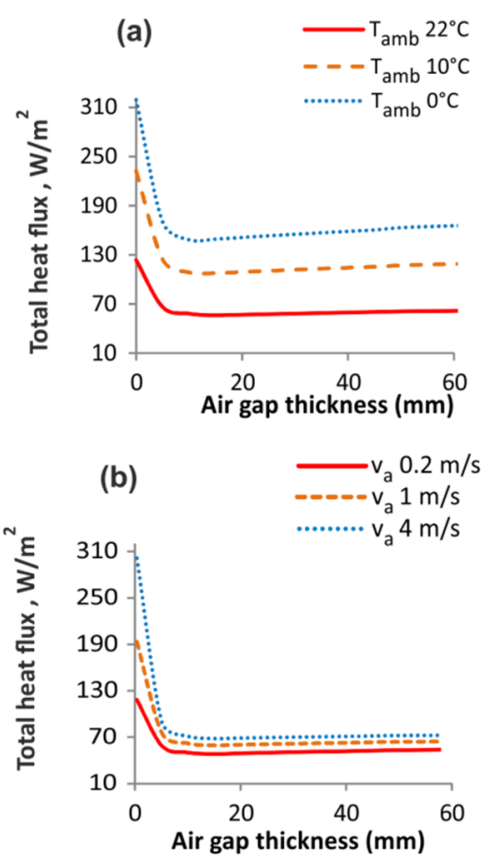

(c)

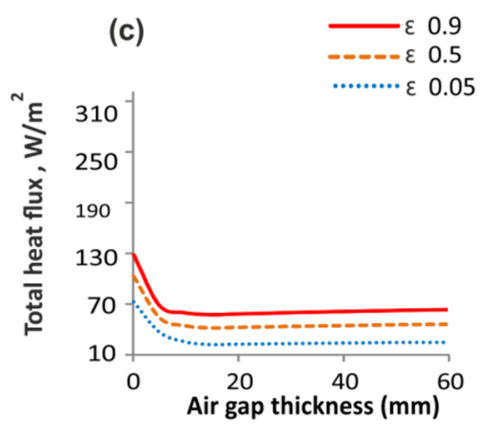

(d)

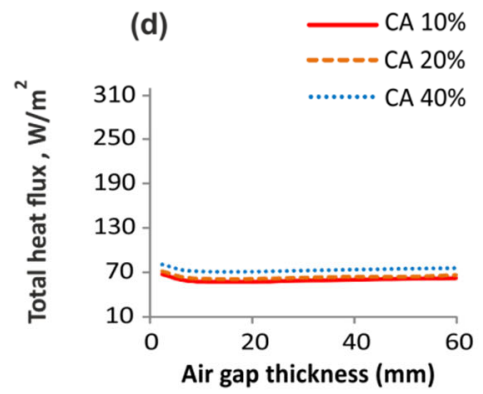

2
Middle

Right
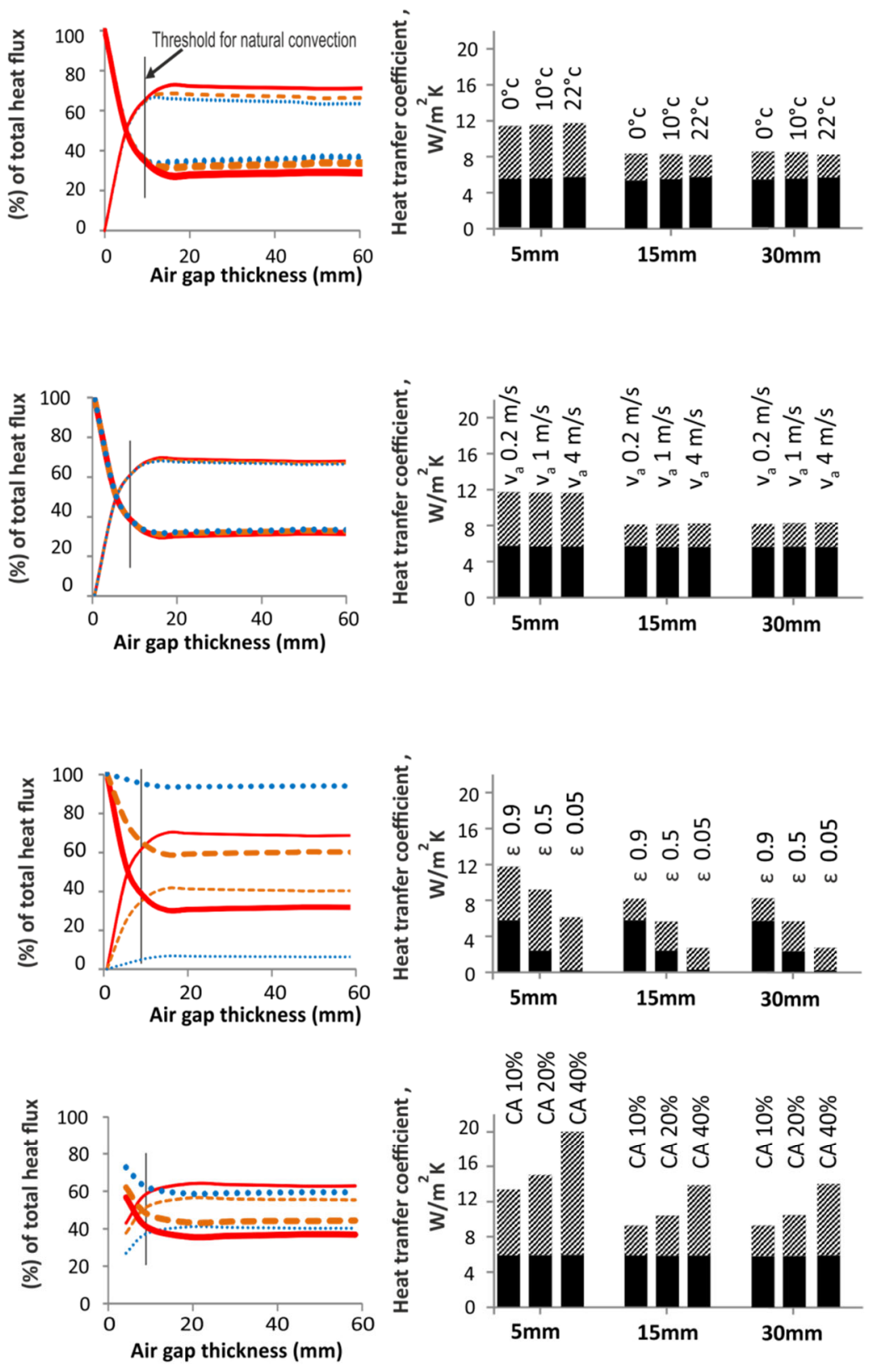

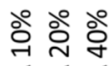

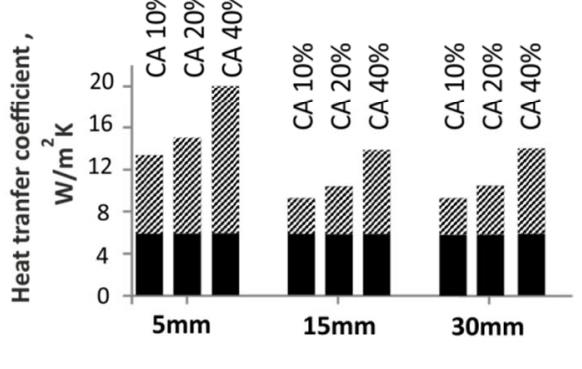

$\overline{--\ldots-. .}$ Radiative $\overline{\ldots . . .} \begin{gathered}\text { Conductive } \\ \text { and/or } \\ \text { Convective }\end{gathered}$

\% Conductive and/or convective - Radiative

Figure 6 Simulated total heat flux (left), contribution of the individual heat transfer mechanisms (middle) and effect of parameters on heat transfer mechanism (right) depending on ambient temperature (a), ambient air velocity (b), fabric emissivity (c), and contact area 
1 Table 7 Relative Error (RE) and Coefficient of variation (CV) for the different groups of validation exposures.

\begin{tabular}{|c|c|c|c|c|c|}
\hline & & Experimental & Theoretical & Theoretical ${ }^{*}$ & \\
\hline & No. & $\begin{array}{l}\text { Heat flux }\left[\mathrm{W} / \mathrm{m}^{2}\right] \\
\quad(\mathrm{CV}[\%])\end{array}$ & $\begin{array}{l}\text { Heat flux }\left[\mathrm{W} / \mathrm{m}^{2}\right] \\
(\mathrm{CV}[\%])\end{array}$ & $\begin{array}{l}\text { Heat flux }\left[\mathrm{W} / \mathrm{m}^{2}\right] \\
(\mathrm{CV}[\%])\end{array}$ & $\mathrm{RE}^{\mathrm{RE}}{ }^{*}[\%]$ \\
\hline & 1 & $65.6(1.1)$ & 64.8 (n/a) & $\mathrm{n} / \mathrm{a}$ & 1.2 \\
\hline$\frac{\pi}{0} \cdot \frac{0}{\underline{n}}$ & 2 & $55.3(2.1)$ & $61.4(\mathrm{n} / \mathrm{a})$ & $\mathrm{n} / \mathrm{a}$ & 11.0 \\
\hline$\frac{O}{0} \frac{\bar{\sigma}}{\complement}$ & 3 & $62.2(1.1)$ & 62.1 (n/a) & $\mathrm{n} / \mathrm{a}$ & 0.1 \\
\hline 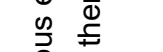 & 4 & $77.0(\mathrm{n} / \mathrm{a})$ & $72.2(\mathrm{n} / \mathrm{a})$ & $\mathrm{n} / \mathrm{a}$ & 6.2 \\
\hline$\stackrel{\Xi}{\frac{\Phi}{d}} \frac{0}{5}$ & 5 & 75.0 (n/a) & 78.1 (n/a) & $\mathrm{n} / \mathrm{a}$ & -4.2 \\
\hline 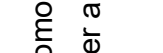 & 6 & $121.0(n / a)$ & $118.0(n / a)$ & $\mathrm{n} / \mathrm{a}$ & 2.4 \\
\hline & 7 & $128.0(\mathrm{n} / \mathrm{a})$ & $127.3(\mathrm{n} / \mathrm{a})$ & $\mathrm{n} / \mathrm{a}$ & 0.5 \\
\hline & Average & $C V[\%]=1.4$ & $\mathrm{CV}[\%]=\mathrm{n} / \mathrm{a}$ & $C V[\%]=n / a$ & $\operatorname{RE}[\%]=3.7(n / a)$ \\
\hline & 8 & $71.1(4.9)$ & $64.4(0.1)$ & $61.4(\mathrm{n} / \mathrm{a})$ & $9.3 / 13.6$ \\
\hline d & 9 & $70.3(2.3)$ & $64.2(0.5)$ & $60.3(\mathrm{n} / \mathrm{a})$ & $8.7 / 14.3$ \\
\hline$\frac{0}{0} \overline{\frac{\pi}{6}}$ & 10 & $67.5(1.6)$ & $76.3(0.3)$ & $71.9(\mathrm{n} / \mathrm{a})$ & $-13.0 /-6.5$ \\
\hline$\stackrel{\infty}{\Xi}$ & 11 & $68.1(2.6)$ & $67.7(0.3)$ & $62.0(\mathrm{n} / \mathrm{a})$ & $0.6 / 9.0$ \\
\hline$\stackrel{0}{0}$ & 12 & $70.2(6.8)$ & $76.6(0.3)$ & 67.1 (n/a) & $-9.1 / 4.4$ \\
\hline 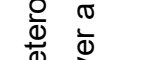 & 13 & $72.0(3.6)$ & $80.8(0.1)$ & $81.3(\mathrm{n} / \mathrm{a})$ & $-12.2 /-12.9$ \\
\hline I $\underline{\underline{\sigma}}$ & 14 & $85.5(2.5)$ & $96.2(0.4)$ & $101.3(\mathrm{n} / \mathrm{a})$ & $-12.4 /-18.4$ \\
\hline & Average & $C V[\%]=3.5$ & $C V[\%]=0.3$ & $C V[\%]=n / a$ & $\operatorname{RE}[\%]=9.3(11.3)$ \\
\hline $\bar{\Phi} \bar{\sigma}=$ & 15 & $119.3(1.0)$ & $129.0(3.6)$ & $126.0(n / a)$ & $-8.1 /-5.6$ \\
\hline 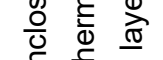 & 16 & $138.9(3.3)$ & $124.5(0.8)$ & $123.8(\mathrm{n} / \mathrm{a})$ & $10.4 / 10.9$ \\
\hline 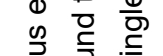 & 17 & $140.7(1.5)$ & $131.5(4.9)$ & $126.3(\mathrm{n} / \mathrm{a})$ & $6.5 / 10.3$ \\
\hline 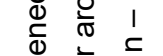 & 18 & $136.7(0.3)$ & $147.3(11.1)$ & $126.8(\mathrm{n} / \mathrm{a})$ & $-7.7 / 7.2$ \\
\hline 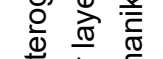 & 19 & $43.5(4.2)$ & $43.8(4.9)$ & $42.57(\mathrm{n} / \mathrm{a})$ & $-0.5 / 2.2$ \\
\hline$\stackrel{\oplus}{I} \cdot \overline{\bar{\sigma}}$ & 20 & $42.6(1.4)$ & $49.0(11.2)$ & $42.61(\mathrm{n} / \mathrm{a})$ & $-14.9 / 0.1$ \\
\hline & Averag & $C V[\%]=1.2$ & $C V[\%]=6.1$ & $C V[\%]=n / a$ & $\operatorname{RE}[\%]=8.0(6.1)$ \\
\hline 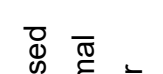 & 21 & $81.6(6.4)$ & $\mathrm{n} / \mathrm{a}$ & $97.3(\mathrm{n} / \mathrm{a})$ & -19.2 \\
\hline 응 & 22 & $82.5(2.2)$ & $\mathrm{n} / \mathrm{a}$ & $82.0(n / a)$ & 0.6 \\
\hline 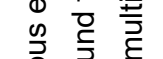 & 23 & $127.8(7.3)$ & $\mathrm{n} / \mathrm{a}$ & $121.6(\mathrm{n} / \mathrm{a})$ & 4.8 \\
\hline 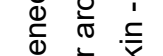 & 24 & $93.9(1.6)$ & $\mathrm{n} / \mathrm{a}$ & $108.6(n / a)$ & -15.7 \\
\hline 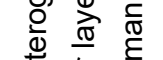 & 25 & $93.7(1.2)$ & $\mathrm{n} / \mathrm{a}$ & $91.5(\mathrm{n} / \mathrm{a})$ & 2.4 \\
\hline$\frac{\Phi}{1} \cdot \overline{\bar{\sigma}}$ & 26 & $120.4(1.2)$ & $\mathrm{n} / \mathrm{a}$ & $136.5(\mathrm{n} / \mathrm{a})$ & -13.3 \\
\hline & Average & $C V[\%]=3.3$ & $C V[\%]=n / a$ & $C V[\%]=n / a$ & $\operatorname{RE}[\%]=(9.3)$ \\
\hline
\end{tabular}

$3{ }^{*}$ : When air gap thickness is discretized into only two elements such as contact area and mean air gap thickness for the remaining surface area 


\section{Discussion}

The theoretical model for sensible heat transfer from human body to the environment through clothing ensemble was successfully developed. The model includes new aspects such as spatial heterogeneity of enclosed air layers and natural convection in both enclosed and boundary air layers in addition to conduction and radiation. We observed that the highest effect of heterogeneous air gap was observed for body parts with high contact area and relatively low average air gap thickness compared to body parts with relatively low contact area and higher air gap. As shown in Figure 7(a), a consideration of the heterogeneity of enclosed air layer can substantially improve the accuracy of heat transfer prediction, e.g. for the heterogeneous air gap on thermal cylinder and anatomically shaped thermal manikin accuracy can be improved up to three times. Finally, the model was validated for homogeneous, regularly heterogeneous and realistic (irregular) air gaps in single- and multi-layer ensembles in a wide range of ambient conditions. A good agreement was observed for simulated and measured heat fluxes when the detailed distribution of air gap as an input was used resulting in an average error of $7 \%$ (between $-14.9 \%$ and $11 \%$ ) as compared to experimental data variability of $2 \%$. The results were also in a reasonable agreement when air gap data were approximated from the air gap model resulting in an average error of $9.3 \%$ (between $-19.2 \%$ and $4.8 \%$ ) as compared to experimental data variability of $3.3 \%$. The accuracy of the model depends on spatial complexity and availability of detailed distribution of air gap, as for a homogeneous air layer the average error was $3.7 \%$ which increased up to $9.3 \%$ for heterogeneous air layers.

The model precisely simulates the heat flux for homogeneous air gap thickness (cases 1-7, Table 2), with an average error of $3.7 \%$ as compared to standard deviation of the experimental data of $1.4 \%$ (Table 7). A good agreement was observed for cases $1-3$ consisted of various air gap thicknesses $(10,30$ and $50 \mathrm{~mm})$, where for larger air gap thickness of $30 \mathrm{~mm}$ and $50 \mathrm{~mm}$, natural convection was observed in the experiments [15]. Particularly, the model adequately simulated the heat flux for larger air gap thickness (Fig. 5(a)). By neglecting natural convection in their model, Mert et al. [15] observed an error of $15 \%$ for the largest air gap $(50 \mathrm{~mm})$. This error was reduced to $1.2 \%$ by considering natural convection in this study. Depending on the temperature difference and thickness of enclosed air, natural convection may have a pronounced effect on the total sensible heat transfer. The theoretical model presented in this paper considers natural convection in the vertical rectangular cavity for a wide range of aspect ratios (1 to 110). Our clothing model showed also good performance when forced convective air flow $\left(v_{a}=1 \mathrm{~m} / \mathrm{s}\right)$ was present in the boundary air layer (cases 4-7, Table 2). As shown in Figure 5 (a), simulated and measured heat flux was in very good agreement with an average error less than $4 \%$ (between $-4.2 \%$ and $6.2 \%$ ) (Table 7 ).

When the heterogeneity of the enclosed air layer was considered the performance of the theoretical clothing model was continuously good with an average error of $9.3 \%$. Mert et al. [15] have observed that the heterogeneity of enclosed air plays an important role in heat transfer. It tends to increase the heat loss as compared to homogenous case even if the average air 
gap thickness remained constant, because of increased conduction resulted from the contact between skin and fabric. In reality the thickness of an enclosed air layer varies between 0 to $55 \mathrm{~mm}$ and contact area varies up to 3\%-67\% for different body parts depending on clothing fit level $[18,20,22]$. The assumption of a homogeneous air gap or full contact between skin and fabric clearly contradicts real life scenarios and such a model including homogeneous air gaps only has limited applicability for the anatomically shaped thermal manikin or the human body. For a spatially heterogeneous air layer, the surface temperature of the fabric varies at different distances from the skin (thickness of enclosed air layer). The heterogeneous temperature distribution on the fabric surface has a more pronounced effect on heat loss in the enclosed air layer and in the boundary air layer. With the method suggested in this paper in section 2.4, the clothing model calculates individual temperatures at each element and a precise temperature distribution in a heterogeneous air layer can be obtained, as shown in Figure 7 (a). With this more accurate information about the temperature profile, it is possible to calculate the heat flux for heterogeneous air gaps. As shown in Figure 5 (b), the theoretically simulated and the measured values of heat flux are in good agreement with an average error of $9.3 \%$ (between $-13 \%$ and $9.3 \%$ ). The induced error due to neglected natural convection and spatial heterogeneity was $22 \%$ [15], which can be improved to $9.3 \%$ with the model suggested in this paper.

The theoretical model suggested in this paper is applicable not only to simplified manikins such as the thermal cylinder but also to anatomically-shaped thermal manikins due to its ability to consider spatial heterogeneity, which was confirmed by the validation in cylindrical heterogeneous setting. The model accurately predicted the heat flux from the anatomically-shaped thermal manikin for single layer t-shirt (cases 15-20, Table 4, Figure 5(c)) with an average error of $8 \%$ (between $-14.9 \%$ and $10.4 \%$ ). For the multi-layer garment the air gap thickness distribution was approximated from the air gap model [24] in form of percentage of contact area and the average air gap thickness for the remaining area. As shown in Figure 5 (d), theoretically simulated and measured values of heat flux were in a reasonable agreement with an average error of $9.3 \%$ (between $-19.2 \%$ and $4.8 \%$ ). The reason for the reduced accuracy for multi-layer ensemble cases could be the air gap approximation error as reported by Psikuta et al. [24] and lack of the detailed distribution of air gap thickness ( $w_{j}$ distribution) that can be provided only from the 3D scanning method [10]. For multi-layer clothing, it will be difficult to obtain air gap distributions of inner layers of clothing; in such cases, the contact area and the average air gap thickness could be approximated from the model developed by Psikuta et al. [24] as in this study. The assumption of average air gap thickness along with contact area (between skin and fabric) produces reliable results, so for analysis of heat and mass transfer in multilayer clothing the presented model can be very useful.

In present study, we have demonstrated two approaches for discretization of air layer thickness distribution. In the first approach, the enclosed air layer is discretised into several elements using 3D scanning method (element size of $1 \mathrm{~mm}$ ), in the second approach we discretised the 
1 using local air gap thickness model as discussed in section 2.6.1. The local air gap thickness

2 model can predict the air gap thickness and contact area for fourteen body parts for the casual

3 garments without requiring 3D scanner (the firefighters clothing and other clothing ensembles

4 where stiffness of fabric is very high, this model may not be applicable). Both approaches yield

5 good accuracy of the heat flux prediction, and have similar average relative error on thermal

6 cylinder of $9.3 \%$ and $11.3 \%$ and on thermal manikin $8.0 \%$ and $6.1 \%$, as presented in Table 7 .

7 In the anatomically shaped thermal manikin, different body sectors share a common en-

8 closed air layer such as back and pelvis, upper and lower arm, and upper and lower leg. In

9 the vertical position, low density heated air raises and low temperature air sinks because of

10 the buoyancy effect. Due to this effect, the body sectors that have common enclosed air layer can have intersegmental heat exchange affecting the local heat flux. The theoretical model presented in this paper does not consider this intersegmental heat exchange, thus, the body sectors that share common enclosed air should be considered as one for a proper representation in the model. For example, in the validation case with the single-layer garment loosely hanging around the waistline, the back and buttocks have a common enclosed air layer. Due to natural convection, heated air raises towards the back region and brings along the energy transferred to the fluid at the buttock region, while low temperature air sinks along the inner side of the garment losing its thermal energy to the environment and cooling the buttocks region. Figure 7 (b) demonstrates the magnitude of the intersegmental heat exchange by comparing individual and lumped heat fluxes for back and buttocks sharing a common enclosed air space with present free convection (case 15, Table 4). 
(a)

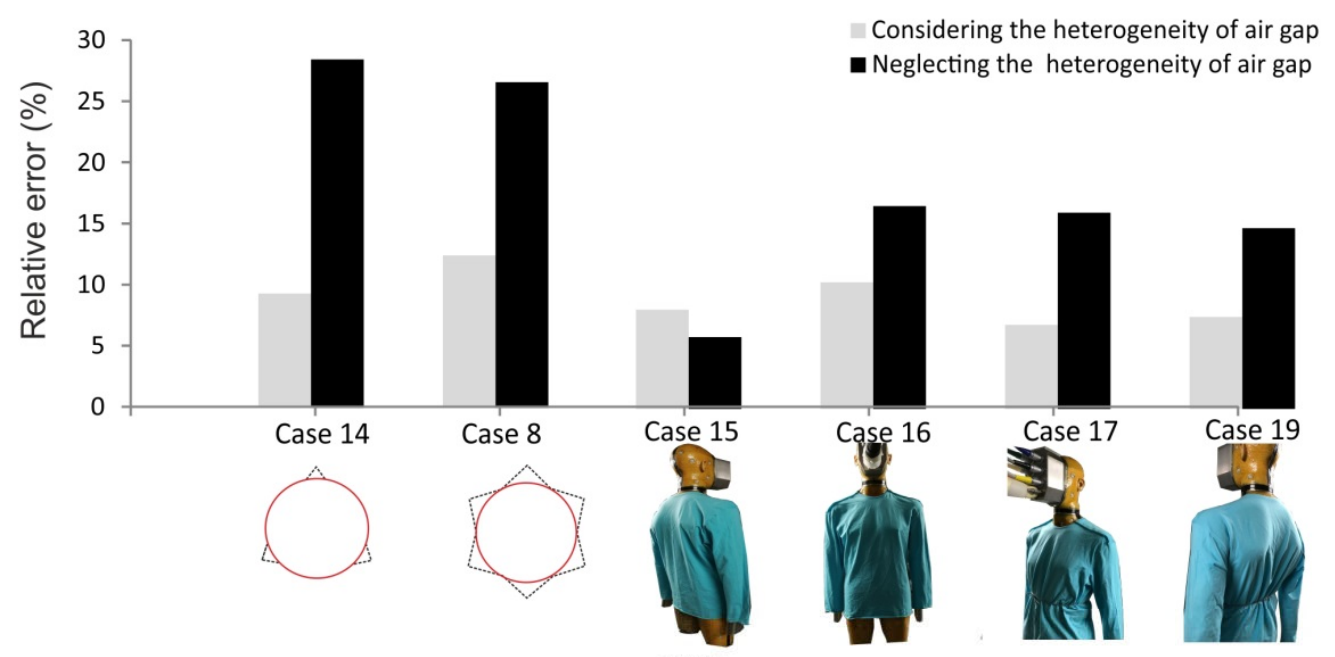

(b) Distance from the skin ( $\mathrm{mm}$ )

$\rightarrow$ Fabric temperature

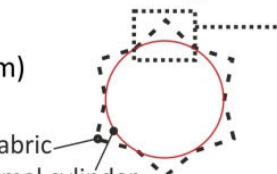
Thermal.cylinder

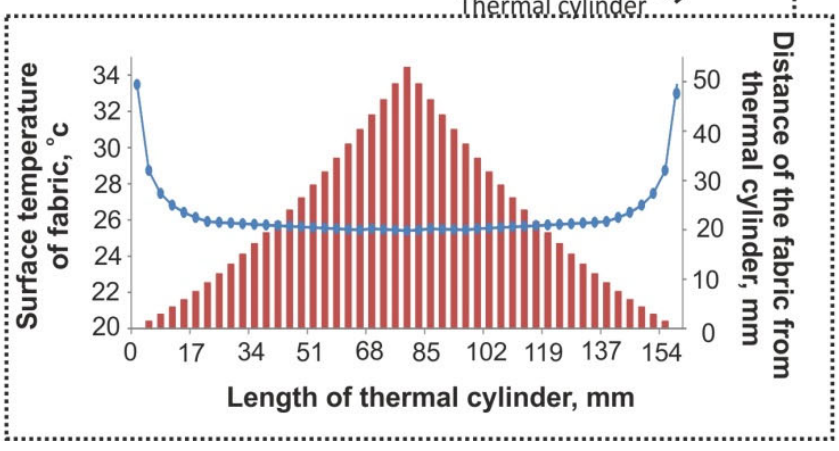

(c)

口Theoretical

- Experimental

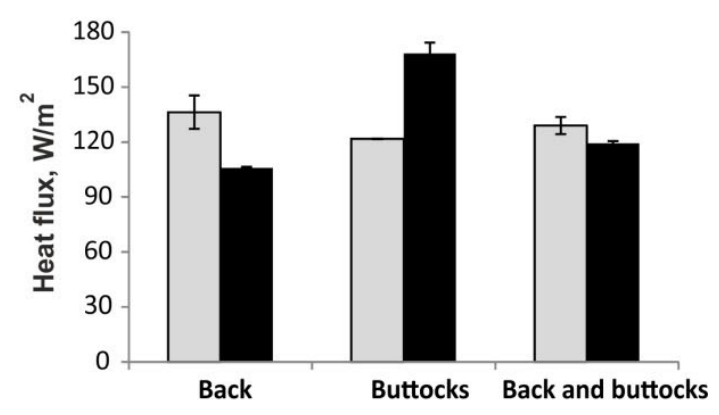

Figure 7. increased accuracy when heterogeneity of air layer is considered (Relative error in comparison to experimental data)(a), Temperature distribution on the surface of fabric at different distance from the skin (Case 8, Table 3, Figure 3 ) 3) (b) , Effect of intersegmental heat exchange demonstrated by individual and lumped heat fluxes for back and buttocks sharing common enclosed air space with present free convection(c)

To understand the effect of various ambient parameters (temperature and air speed), material properties (emissivity of fabric), and distribution of average air gap and contact area on total heat transfer and various heat transfer mechanisms parametric study were performed and results are presented in Figure 6.

- The temperature difference between skin and ambient air is one of the most influential parameter for total heat flux amongst all studied parameters in realistic exposure range. With increasing the temperature difference between skin and ambient air, the total heat flux from human body also increases as shown in Figure 6 (a: left). However, radiative heat transfer coefficient is relatively constant irrespective of distance and temperature. The conductive heat transfer coefficient decreases with increase in distance (Fourier's law) and after a certain distance due to natural convection it becomes constant as shown 
in Figure 6 (a: middle). The threshold for natural convection depends on the temperature gradient. At temperature gradients of $35^{\circ} \mathrm{C}, 25^{\circ} \mathrm{C}$ and $13^{\circ} \mathrm{C}$, the threshold for natural convection is $9 \mathrm{~mm}, 10 \mathrm{~mm}$ and $14 \mathrm{~mm}$, respectively.

- The ambient air speed affects forced convective heat transfer in boundary air layer; with an increase in air speed, the total heat flux from human body also increases Figure 6 (b: left). However, a change in air speed in the boundary air layer does not affect the radiative and conductive and/or convective heat transfer coefficient in an enclosed air layer as shown in Figure 6 (b: right).

- The emissivity of fabric affects the radiative heat transfer coefficient, and reducing the emissivity of fabric results in decreased total heat flux from human body to the environment Figure 6 (c: left). The lower emissivity of fabric reduces the radiative heat transfer coefficient in an enclosed air layer as shown in Figure 6 (c: right).

- The contact area between skin and fabric results in higher total heat flux Figure 6 (d: left), due to the thermal conduction between skin and fabric. As shown in Figure 6 (d: right), the contact area between skin and fabric does not affect the radiative heat transfer coefficient but the conductive heat transfer coefficient increases with increase in contact area.

As shown in Figure 6 (middle), at low air gap thickness, the conductive heat transfer mechanism is predominant and as distance increases, the conductive heat transfer decreases. After a certain distance due to natural convection, the composition of convective heat transfer remains constant.

As discussed, environmental parameters have a pronounced effect on total heat transfer but do less affect the heat transfer mechanisms; on the other hand material properties such as emissivity of fabric and contact area have greater influence on heat transfer mechanisms. With the help of the model developed in this paper, it is possible to optimize the localized thermal insulation for each body part by clothing fit (ease allowances), and emissivity of the fabric for given ambient conditions.

The clothing model developed in this study simulates conductive heat transfer in one dimension, and lateral exchange of heat due to conduction is neglected. The clothing model is predominantly applicable for quasi steady-state exposures, which is the case for many applications, as the thermal inertia of fabric and air is relatively low, and only a small error would result in moderately transient exposure conditions. However, in extremely transient conditions, for example when suddenly exposed to radiant heat in firefighting, this clothing model may not be adequate. The ability to simulate the heat transfer for spatially heterogeneous enclosed air layer and robustness of model has been proven during in-depth systematic validation. Hence, the developed model is good alternative to the numerical model, which is computationally very expensive and time consuming. The presented model also provides one step forward with regard to considering dynamic air gaps (body movement) and helps to make more accurate predictions for more realistic considerations of enclosed air layer for lo- 
1 cal body parts. The clothing model presented in this paper is simulating sensible heat trans-

2 fer in detail, and can be coupled with a vapour transport (gradient of water vapour partial

3 pressure) model providing fundamental basis for computation/estimation of wet conduction

4 and wicking due to its ability of considering spatial heterogeneity. 


\section{Conclusion}

In this study, a theoretical model for sensible heat transfer was developed that considers the natural convection and spatial heterogeneity of enclosed air layers. The model was successfully validated against various experimental datasets obtained using a thermal cylinder and an anatomically shaped thermal manikin with homogenous and heterogeneous air gaps and single- and multi-layer clothing in a wide range of air gaps ( 0 to more than $50 \mathrm{~mm}$ ) and temperatures $\left(-10^{\circ} \mathrm{C}\right.$ to $\left.24^{\circ} \mathrm{C}\right)$. Moreover, we have demonstrated that the model can address even very complex exposure scenarios and clothing including the spatial heterogeneity and the contact area between skin and fabric having pronounced influence on heat loss. It can be concluded that depending on the temperature difference and the thickness of the enclosed air layer, natural convection plays an important role in total sensible heat flux. Different leisure activities and occupational tasks include very limited human movement such as resting, driving, sleeping etc. Many of such applications may be challenging when using state-of-art methods such as thermal manikins to evaluate the heat exchange between the body and environment (costly and time consuming, not portable, generating extreme climatic condition in climatic chamber) whereas this model can be applied quickly and fully virtually. The theoretical model developed in this paper can help in analysing the effect of various parameters on heat transfer, and optimizing the product using parametric study.

The theoretical model presented in this paper provides critical inputs to clothing science for designing and development of protective and functional clothing, thermo-physiological simulations, and in analysis of thermal comfort in various disciplines, such as apparel, automotive, medtech and indoor research.

\section{Acknowledgements}

The work was supported by the HEAT-SHIELD project within EU Horizon 2020 program under Grand RIA 668786-1. The authors gratefully acknowledge Dr. Emel Mert from Laboratory for Biomimetic Membranes and Textiles at Empa for introduction to 3D scanning method and Aeberhard Max from Laboratory for Biomimetic Membranes and Textiles at Empa for his technical support during thermal measurements. 
[1] U. Danielsson, "Convection coefficients in clothing air layers," PhD Doctoral Thesis, Department of energy technology, The royal institute of technology, Stockholm, 1993.

[2] J. C. Gretton, D. B. Brook, H. M. Dyson, and S. C. Harlock, "Moisture vapor transport through waterproof breathable fabrics and clothing systems under a temperature gradient," Textile Research Journal, vol. 68, no. 12, pp. 936-941, Dec 1998.

[3] J. L. Spencer-Smith, "The Physical Basis of Clothing Comfort Part 2: Heat Transfer Through Dry Clothing Assemblies," Clothing Research Journal, vol. 5, no. 1, pp. 3-17, 1977.

[4] B. Farnworth, "A NUMERICAL-MODEL OF THE COMBINED DIFFUSION OF HEAT AND WATERVAPOR THROUGH CLOTHING," Textile Research Journal, vol. 56, no. 11, pp. 653-665, Nov 1986.

[5] W. A. Lotens and G. Havenith, "CALCULATION OF CLOTHING INSULATION AND VAPOR RESISTANCE," Ergonomics, vol. 34, no. 2, pp. 233-254, Feb 1991.

[6] E. H. Wissler and G. Havenith, "A simple theoretical model of heat and moisture transport in multi-layer garments in cool ambient air," Eur J Appl Physiol, vol. 105, no. 5, pp. 797-808, Mar 2009.

[7] H. J. Wu and J. T. Fan, "Study of heat and moisture transfer within multi-layer clothing assemblies consisting of different types of battings," (in English), International Journal of Thermal Sciences, Article vol. 47, no. 5, pp. 641-647, May 2008.

[8] K. Min, Y. Son, C. Kim, Y. J. Lee, and K. Hong, "Heat and moisture transfer from skin to environment through fabrics: A mathematical model," (in English), Int. J. Heat Mass Transf., Article vol. 50, no. 25-26, pp. 5292-5304, Dec 2007.

[9] H. K. Song and S. P. Ashdown, "Development of Automated Custom-Made Pants Driven by Body Shape," Clothing and Textiles Research Journal, vol. 30, no. 4, pp. 315-329, 2012.

[10] A. Psikuta, J. Frackiewicz-Kaczmarek, E. Mert, M.-A. Bueno, and R. M. Rossi, "Validation of a novel 3D scanning method for determination of the air gap in clothing," Measurement, vol. 67, pp. 61-70, 2015.

[11] N. Ismail, N. Ghaddar, and K. Ghali, "Improving local ventilation prediction by accounting for inter-segmental ventilation," Textile Research Journal, vol. 87, no. 5, pp. 511-527, Mar 2017.

[12] Udayraj and F. M. Wang, "A three-dimensional conjugate heat transfer model for thermal protective clothing," International Journal of Thermal Sciences, vol. 130, pp. 28-46, Aug 2018.

[13] Udayraj, P. Talukdar, A. Das, and R. Alagirusamy, "Heat and mass transfer through thermal protective clothing - A review," International Journal of Thermal Sciences, vol. 106, pp. 32-56, Aug 2016.

[14] N. Ismail, N. Ghaddar, and K. Ghali, "Electric circuit analogy of heat losses of clothed walking human body in windy environment," International Journal of Thermal Sciences, vol. 127, pp. 105-116, May 2018.

[15] E. Mert, A. Psikuta, M. A. Bueno, and R. M. Rossi, "Effect of heterogenous and homogenous air gaps on dry heat loss through the garment," Int. J. Biometeorol., vol. 59, no. 11, pp. 1701-1710, Nov 2015.

[16] Udayraj, P. Talukdar, A. Das, and R. Alagirusamy, "Numerical investigation of the effect of air gap orientations and heterogeneous air gap in thermal protective clothing on skin burn," International Journal of Thermal Sciences, vol. 121, pp. 313-321, Nov 2017.

[17] E. Mert, S. Bohnisch, A. Psikuta, M. A. Bueno, and R. M. Rossi, "Contribution of garment fit and style to thermal comfort at the lower body," Int. J. Biometeorol., vol. 60, no. 12, pp. 1995-2004, Dec 2016.

[18] J. Frackiewicz-Kaczmarek, A. Psikuta, M. A. Bueno, and R. M. Rossi, "Air gap thickness and contact area in undershirts with various moisture contents: influence of garment fit, fabric 
structure and fiber composition," Textile Research Journal, vol. 85, no. 20, pp. 2196-2207, Dec 2015.

[19] K. Ghali, N. Ghaddar, and B. Jones, "Modeling of heat and moisture transport by periodic ventilation of thin cotton fibrous media," Int. J. Heat Mass Transf., vol. 45, no. 18, pp. 37033714, Aug 2002, Art no. Pii s0017-9310(02)00088-1.

[20] E. Mert, A. Psikuta, M. A. Bueno, and R. M. Rossi, "The effect of body postures on the distribution of air gap thickness and contact area," (in English), Int. J. Biometeorol., Article vol. 61, no. 2, pp. 363-375, Feb 2017.

[21] A. Psikuta, J. Frackiewicz-Kaczmarek, I. Frydrych, and R. Rossi, "Quantitative evaluation of air gap thickness and contact area between body and garment," Textile Research Journal, vol. 82, no. 14, pp. 1405-1413, Sep 2012.

[22] J. Frackiewicz-Kaczmarek, A. Psikuta, M. A. Bueno, and R. M. Rossi, "Effect of garment properties on air gap thickness and the contact area distribution," Textile Research Journal, vol. 85, no. 18, pp. 1907-1918, Nov 2015.

[23] T. Mah and G. W. Song, "Investigation of the Contribution of Garment Design to Thermal Protection. Part 1: Characterizing Air Gaps using Three-dimensional Body Scanning for Women's Protective Clothing," Textile Research Journal, vol. 80, no. 13, pp. 1317-1329, Aug 2010.

[24] A. Psikuta, E. Mert, S. Annaheim, and R. M. Rossi, "Local air gap thickness and contact area models for realistic simulation of human thermo-physiological response," Int. J. Biometeorol., journal article vol. 62, no. 7, pp. 1121-1134, July 012018.

[25] A. Rincon-Casado, F. J. S. de la Flor, E. C. Vera, and J. S. Ramos, "New natural convection heat transfer correlations in enclosures for building performance simulation," Engineering Applications of Computational Fluid Mechanics, vol. 11, no. 1, pp. 340-356, 2017.

[26] E. Shewen, K. G. T. Hollands, and G. D. Raithby, "Heat transfer by natural convection across a vertical air cavity of large aspect ratio," Journal of Heat Transfer-Transactions of the Asme, vol. 118, no. 4, pp. 993-995, Nov 1996.

[27] ISO 9920:2007(E), "Ergonomics of the thermal environment - Estimation of thermal insulation and water vapor resistance of a clothing ensemble " vol. Second edition 2007-06-01.

[28] Standard Test Method for Thermal and Evaporative Resistance of Clothing Materials Using a Sweating Hot Plate, 2002.

[29] J. C. Dixon, "Appendix B: Properties of Air," in The Shock Absorber Handbook: John Wiley \& Sons, Ltd, 2007, pp. 375-378.

[30] A. J. G. Yunus A. Cengel, HEAT AND MASS TRANSFER: FUNDAMENTALS \& APPLICATIONS, FIFTH EDITION. 2 Penn Plaza, New York, NY 10121: McGraw-Hill Education, 2015.

[31] F. Lyman and R. S. H. Norman, "THE COMFORT AND FUNCTION OF CLOTHING," Harris Research Laboratories, Division of Gillette Research Institute, Harris Research Laboratories, Rockville, Maryland, June 1969 June 1969.

[32] M. Dumicz, "Development and validation of free convection model for air gaps," MASTER OF SCIENCE, DEPARTMENT OF AIR-CONDITIONING AND HEATING, WARSAW UNIVERSITY OF TECHNOLOGY, WARSAW, 2016.

[33] D. B. Spalding and N. Afgan, Heat transfer and turbulent buoyant convection: studies and applications for natural environment, buildings, engineering systems (no. Bd. 2). Hemisphere Pub. Corp. : in association with McGraw-Hill International Book Co., 1977.

[34] Macgrego.Rk and A. F. Emery, "FREE CONVECTION THROUGH VERTICAL PLANE LAYERS MODERATE AND HIGH PRANDTL NUMBER FLUIDS," Journal of Heat Transfer, vol. 91, no. 3, pp. 391-\&, 1969. 
[35] D. Fiala, G. Havenith, P. Bröde, B. Kampmann, and G. Jendritzky, "UTCI-Fiala multi-node model of human heat transfer and temperature regulation," Int. J. Biometeorol., journal article vol. 56, no. 3, pp. 429-441, May 012012.

[36] K. Kubaha, D. Fiala, J. Toftum, and A. H. Taki, "Human projected area factors for detailed direct and diffuse solar radiation analysis," Int. J. Biometeorol., vol. 49, no. 2, pp. 113-129, Nov 2004.

[37] M. H. Richards M, Broede P, Candas V, den Hartog E, Holmer I, Nocker W, Havenith G, "Study of materials to investigate the effects of moisture on the heat transfer through the protective clothing " Empa, Switzerland Report on ThermProject G6RD-CT-2002-00846, 2002.

[38] R. Rossi, M. Weder, R. Gross, and F. Kausch, "Influence of air permeability on thermal and moisture transport through clothing," In: Proceedings of the 1st European conference on protective clothing,Stockholm, Sweden; pp. 12-16, 20002000.

[39] S. Annaheim, L.-c. Wang, A. Psikuta, M. P. Morrissey, M. A. Camenzind, and R. M. Rossi, "A new method to assess the influence of textiles properties on human thermophysiology. Part I: Thermal resistance," International Journal of Clothing Science and Technology, vol. 27, no. 2, pp. 272-282, 2015.

[40] T. Zimmerli and M. S. Weder, "Protection and comfort - A sweating torso for the simultaneous measurement of protective and comfort properties of PPE," in Performance of Protective Clothing, 6th Volume, vol. 1273, J. O. Stull and A. D. Schwope, Eds. (American Society for Testing and Materials Special Technical Publication, 1997, pp. 271-280.

[41] A. Psikuta, "Development of an 'artificial human' for clothing research," [Ph.D. thesis], De Montfort University 2009.

[42] M. G. M. Richards and E. A. McCullough, Revised interlaboratory study of sweating thermal manikins including results from the sweating agile thermal manikin (Performance of Protective Clothing: Global Needs and Emerging Markets: 8th Symposium). W Conshohocken: American Society Testing and Materials, 2005, pp. 27-39.

[43] M. G. M. Richards, A. Psikuta, and D. Fiala, "Current development of thermal sweating manikins at Empa," presented at the Thermal Manikins and Modelling, 2006. [Online]. Available: $<$ Go to ISI ://WOS:000245322500020.

[44] Mark. A, "The impact of the individual layers in multi-layer clothing systems on the distribution of the air gap thickness and contact area," Master thesis, Albstadt-Sigmaringen University, Albstadt, 2013. 